\title{
Adverse obstetric outcomes after local treatment for cervical preinvasive and early invasive disease according to cone depth: systematic review and meta-analysis
}

\author{
Maria Kyrgiou, ${ }^{1,2}$ Antonios Athanasiou, ${ }^{3}$ Maria Paraskevaidi, ${ }^{1}$ Anita Mitra,,${ }^{1,2}$ Ilkka Kalliala, \\ Pierre Martin-Hirsch, ${ }^{4,5}$ Marc Arbyn, ${ }^{6}$ Phillip Bennett, ${ }^{1,2}$ Evangelos Paraskevaidis ${ }^{3}$
}

IInstitute of Reproductive and

Developmental Biology,

Department of Surgery and

Cancer, Faculty of Medicine,

Imperial College, London, UK

2Queen Charlotte's and

Chelsea-Hammersmith Hospital, Imperial Healthcare NHS Trust,

London, UK

${ }^{3}$ University Hospital of Ioannina, Ioannina, Greece

4Department of Gynaecological Oncology, Lancashire Teaching Hospitals, Preston, UK

${ }^{5}$ Department of Biophotonics, Lancaster University, Lancaster, UK

6Unit of Cancer Epidemiology, Scientific Institute of Public Health, Brussels, Belgium

Correspondence to: M Kyrgiou m.kyrgiou@imperial.ac.uk

Additional material is published online only. To view please visit the journal online.

Cite this as: BMJ 2016;354:i3633 http://dx.doi.org/10.1136/bmj.i3633

Accepted: 26 June 2016

\section{ABSTRACT}

\section{OBJECTIVE}

To assess the effect of treatment for cervical intraepithelial neoplasia (CIN) on obstetric outcomes and to correlate this with cone depth and comparison group used.

\section{DESIGN}

Systematic review and meta-analysis.

DATA SOURCES

CENTRAL, Medline, Embase from 1948 to April 2016

were searched for studies assessing obstetric outcomes in women with or without previous local cervical treatment.

\section{DATA EXTRACTION AND SYNTHESIS}

Independent reviewers extracted the data and performed quality assessment using the NewcastleOttawa criteria. Studies were classified according to method and obstetric endpoint. Pooled risk ratios were calculated with a random effect model and inverse variance. Heterogeneity between studies was assessed with $\mathrm{I}^{2}$ statistics.

\section{MAIN OUTCOME MEASURES}

Obstetric outcomes comprised preterm birth (including spontaneous and threatened), premature rupture of the membranes, chorioamnionitis, mode of delivery, length of labour, induction of delivery, oxytocin use,

\section{WHAT IS ALREADY KNOWN ON THIS TOPIC}

Local cervical treatment has been associated with an increased risk of preterm birth, perinatal morbidity, and mortality in a subsequent pregnancy, which could be associated with depth of excision.

Discrepancies exist regarding the impact of treatment on the risk of subsequent preterm birth and whether CIN acts as a confounder, which might be caused by heterogeneity in comparison groups used in previous studies or different excision depths and/or treatment techniques that have been analysed

\section{WHAT THIS STUDY ADDS}

Increased risk of adverse obstetric outcomes is associated with the treatment technique (excision more than ablation) and radicality, determined by the depth and dimensions of the cone

Although the risk of preterm birth is higher after local treatment for CIN irrespective of the cone depth, the risk increases with increasing cone depth. The increase in risk in small excisions compared with just having CIN remains uncertain and is likely to be small, if any; more data are required

Choice of comparison group might overinflate or underestimate the effect from treatment because of the background increased risk of preterm birth in women with $\mathrm{CIN}$. The increased risk of preterm birth, however, remains significantly increased after treatment, despite the chosen comparator and even in comparisons with women with CIN but no treatment

haemorrhage, analgesia, cervical cerclage, and cervical stenosis. Neonatal outcomes comprised low birth weight, admission to neonatal intensive care, stillbirth, APGAR scores, and perinatal mortality.

\section{RESULTS}

71 studies were included (6338982 participants: 65082 treated/ 6292563 untreated). Treatment significantly increased the risk of overall ( $<37$ weeks; $10.7 \%$ v $5.4 \%$; relative risk $1.78,95 \%$ confidence interval 1.60 to 1.98$)$, severe $(<32-34$ weeks; $3.5 \% \mathrm{v}$ $1.4 \% ; 2.40,1.92$ to 2.99$)$, and extreme ( $<28-30$ weeks; $1.0 \%$ v $0.3 \% ; 2.54,1.77$ to 3.63$)$ preterm birth. Techniques removing or ablating more tissue were associated with worse outcomes. Relative risks for delivery at $<37$ weeks were 2.70 (2.14 to 3.40 ) for cold knife conisation, 2.11 (1.26 to 3.54) for laser conisation, 2.02 (1.60 to 2.55 ) for excision not otherwise specified, 1.56 (1.36 to 1.79) for large loop excision of the transformation zone, and 1.46 (1.27 to 1.66) for ablation not otherwise specified. Compared with no treatment, the risk of preterm birth was higher in women who had undergone more than one treatment (13.2\% v 4.1\%; 3.78, 2.65 to 5.39) and with increasing cone depth ( $\leq 10-12 \mathrm{~mm}$; 7.1\% v 3.4\%; 1.54, 1.09 to 2.18 ; $\geq 10-12 \mathrm{~mm}$ : $9.8 \%$ v 3.4\%, $1.93,1.62$ to $2.31 ; \geq 15-17 \mathrm{~mm}$ : $10.1 \%$ v $3.4 \% ; 2.77,1.95$ to $3.93 ; \geq 20 \mathrm{~mm}: 10.2 \% v$ $3.4 \% ; 4.91,2.06$ to 11.68$)$. The choice of comparison group affected the magnitude of effect. This was higher for external comparators, followed by internal comparators, and ultimately women with disease who did not undergo treatment. In women with untreated $\mathrm{CIN}$ and in pregnancies before treatment, the risk of preterm birth was higher than the risk in the general population ( $5.9 \% \vee 5.6 \% ; 1.24,1.14$ to 1.35$)$. Spontaneous preterm birth, premature rupture of the membranes, chorioamnionitis, low birth weight, admission to neonatal intensive care, and perinatal mortality were also significantly increased after treatment.

\section{CONCLUSIONS}

Women with CIN have a higher baseline risk for prematurity. Excisional and ablative treatment further increases that risk. The frequency and severity of adverse sequelae increases with increasing cone depth and is higher for excision than for ablation.

\section{Introduction}

The mean age of women undergoing local treatment for cervical preinvasive cervical disease (cervical intraepithelial neoplasia or CIN) is similar to the age of women having their first child. Local cervical treatment 
has been correlated to an increased risk of preterm birth, perinatal morbidity, and mortality in a subsequent pregnancy. ${ }^{1-6}$ The underlying mechanism is unclear; hypotheses include immunomodulation relating to infection with human papillomavirus (HPV) affecting parturition pathways and acquired "mechanical weakness" secondary to loss of cervical tissue. ${ }^{78}$

In England alone in 2013-14, about 3.6 million women aged 25-64 attended for cervical screening, and over 23800 cervical procedures were carried out, ${ }^{9}$ nearly all in an outpatient setting. In contrast, in the United States there are about 400000 cases of preinvasive disease a year. ${ }^{10}$ The regulations in colposcopy are more liberal, leading to wide variation in clinical practice. In Germany, treatment for CIN is still commonly performed with the cold knife under general analgesia. ${ }^{11}$ The long term sequelae of treatment therefore remain an important international issue to healthcare professionals and women, whatever the clinical setting.

Since the first systematic review almost a decade ago on reproductive risk associated with treatment ${ }^{1}$ more than 50 observational studies have been published confirming ${ }^{1213}$ or disputing these associations; ${ }^{1415}$ some of these reported data from large population based datasets. Individual attempts to synthesise parts of this rapidly evolving evidence base in small systematic reviews and meta-analyses reached contradictory conclusions ${ }^{1-416-19}$ and initiated debates and confusion within the scientific community. ${ }^{216-19}$ Whether these discrepancies were due to questionable quality of some of these primary and secondary studies or to differences in the explored comparisons, ${ }^{416-18}$ the subject is open to a definitive comprehensive high quality synthesis of the existing evidence that will be highly informative to women, clinicians, and policy makers.

Media publicity has heightened public awareness that treatment for cervical precancer is associated with increased reproductive morbidity. There has been a substantial increase in inquiries from patients and clinicians on the risks associated with different treatment techniques and cone depths ${ }^{2021}$ and as to how this risk can be managed and prevented. With a rapidly evolving evidence base and lack of a robust synthesis of the published literature, these questions are becoming increasingly difficult to answer.

We carried out a systematic review and meta-analysis to explore the impact of treatment for cervical preinvasive and early invasive disease on obstetric outcomes and how this risk could be modified by the cone depth and comparison group.

\section{Methods}

\section{Inclusion criteria and outcomes}

We included all studies that reported on obstetric outcomes (over 24 weeks' gestation) in women who had previously received local cervical treatment for CIN or early invasive cervical cancer compared with outcomes in women with no history of treatment. Studies reporting on the outcomes after two or more treatments were also included. The interventions included any type of treatment: excisional (cold knife conisation; laser conisation; needle excision of the transformation zone, also known as straight wire excision; large loop excision of the transformation zone, also known as loop electrosurgical excisional procedure) or ablative (laser ablation; radical diathermy; cold coagulation; and cryotherapy). In studies that reported on the impact of several techniques, when possible we extracted data for each specific method. If the outcomes were not reported separately for each technique, we analysed the intervention under broader terms-that is, excisional treatment not otherwise specified, ablative treatment not otherwise specified, and treatment not otherwise specified.

Women were included irrespective of the grade of the lesion for both squamous and glandular intraepithelial neoplasia. We excluded studies that did not include an untreated reference population, compared different treatment techniques without an untreated control, or compared outcomes for treatments performed during pregnancy.

Studies were included irrespective of the type of untreated reference population that could have been drawn from one of the following sources: external group from general population that was mostly matched or adjusted for confounders; internal group with self matching of the pregnancies for the same women before and after treatment; internal group of women who had also delivered before treatment; women undergoing colposcopy with or without CIN/biopsy but no treatment; women with high grade disease but no treatment (high grade squamous intraepithelial lesion).

We assessed obstetric outcomes of pregnancies progressing beyond 24 weeks' gestation. We examined both maternal and neonatal outcomes. The maternal outcomes included overall ( $<37$ weeks' gestation), severe ( $<32-34$ weeks), and extreme ( $<28-30$ weeks) prematurity (all preterm birth, iatrogenic and spontaneous). We also assessed preterm birth in singleton and multiple pregnancies, in nulliparous and parous women, for single and repeat cones, for different cone depths and volumes, and for different comparison groups. We further assessed other maternal outcomes that included: overall ( $<37$ weeks' gestation), severe (<32-34), and extreme (<28-30) spontaneous prematuritythat is, non-iatrogenic); threatened preterm birth; premature rupture of the membranes; chorioamnionitis; mode of delivery (caesarean section, instrumental deliveries); length of labour (precipitous, prolonged); induction of labour or use of oxytocin; haemorrhage (antepartum, postpartum); analgesia (epidural, pethidine, not otherwise specified); cervical stenosis; and cervical cerclage. The neonatal outcomes included: low birth weight ( $<2500 \mathrm{~g},<2000 \mathrm{~g},<1500 \mathrm{~g}$, and $<1000 \mathrm{~g}$ ), admission to neonatal intensive unit, perinatal mortality, stillbirth, and Apgar score.

When there was heterogeneity in the cut offs used in different studies for cone depth and classification of prematurity, we grouped these together when possible (that is, 32-34 weeks included both cut offs; $10-12 \mathrm{~mm}$ cone depth included studies grouping at both these cut offs with and without the values equal to these numbers). 
Literature search, data extraction, and risk of bias We searched three electronic databases (CENTRAL, Medline, and Embase) and targeted reports published between 1948 and April 2016. We used keywords including "cervical intraepithelial neoplasia (CIN)”, "cervical cancer”, "LLETZ or LEEP”, “conisation”, “excision”, “pregnancy”, “obstetric”, "preterm birth," and "prematurity". The full strategy is included in appendix 1. In an attempt to identify any articles missed by the initial search or any unpublished data, we hand searched the references of the retrieved articles and meta-analyses and the proceedings of relevant conferences. There was no language restriction.

From each study, we extracted data on the study design and setting, the study population, the interventions examined, the comparison group, the quality of the data and risk of bias, and the outcomes assessed. From each study and for each outcome we retrieved the number of events in treated and untreated women. If necessary, we contacted authors to obtain additional data if the numbers provided in the published report did not allow sufficient precision in the data extraction.

We used the Newcastle-Ottawa score to formally assess the quality of non-randomised cohort studies, ${ }^{22}$ according to the MOOSE checklist. ${ }^{23}$ This scoring system assesses the cohort selection, comparability, and assessment of outcomes to give a maximum score of 9 (highest quality).

Two investigators (MK, AA) independently performed the literature search, assessed the eligibility and quality of the retrieved papers, and performed the data extraction. The two authors then compared the results and disagreements were resolved by discussion. If required, consensus was reached with the involvement of a third investigator (MA).

Data synthesis and assessment of heterogeneity We calculated the risk ratios and 95\% confidence intervals for each reported outcome in the treated versus untreated women for dichotomous outcomes using Cochrane Revman 5 software. We used a random effect model and inverse variance weighting for all meta-analyses. ${ }^{24}$ In studies with multiple treatment groups, we proportionally divided the "shared" comparison group into the number of treatment groups; we treated comparisons between each treatment group and the split comparison group as independent comparisons. If a study presented data for more than one comparison group, we used the external comparison group of women with or without disease in preference to internal controls. If data were not of suitable quality for meta-analysis, we reported the results as a narrative in the text of the review.

We assessed heterogeneity between studies with the Cochran Q test, visual inspection of forest plots, ${ }^{25}$ estimation of the percentage of heterogeneity between studies that cannot be ascribed to sampling variation ( ${ }^{2}$ statistic), ${ }^{26}$ and a formal test of the significance for heterogeneity. ${ }^{27}$ If there was evidence of substantial heterogeneity, the possible reasons for this were investigated and reported.

We performed a series of subgroup analyses. We analysed the data separately for each treatment, in groups of ablative and excisional techniques, and as a whole irrespective of the type of method used. We further analysed the data according to the cone depth. Given the non-randomised nature of the included studies, we assessed whether the choice of comparison group affected the risk estimate for each outcome and overinflated the effect of treatment that could be partly attributed to other confounders. We therefore distinguished the different untreated comparison groups used across studies and performed subgroup analyses for the risk of preterm birth for each individual comparator (external; internal (self matching); internal (pregnancies before treatment); colposcopy but no treatment; high grade squamous intraepithelial lesion but no treatment). Furthermore, we performed sensitivity analysis to assess the impact of the quality of the studies on some selected outcomes. We calculated the median score from the Newcastle-Ottawa scale and performed sensitivity analysis for studies that scored more than the median. We performed subgroup analyses based on the cohort selection in the Newcastle-Ottawa score (truly or somewhat representative) and the comparability of the groups (those with scores of 1 or 2). Finally, we performed meta-regression analysis to assess the impact of some factors on the risk of preterm birth ( $<37$ weeks). These included the quality of the studies (based on the Newcastle-Ottawa score); year of study (1979-89, 199099, 2000-09, 2010-15); type of treatment (excision or ablation); type of comparator (external, internal-pregnancies before treatment, internal-self matching, CIN but no treatment, high grade squamous intraepithelial lesion but no treatment).

\section{Patient involvement}

Patients and the wider public were involved from the outset through informal interviews in the clinic and through patient advocate representative bodies. The research questions and outcomes were developed based on the patients' concerns and priorities. Patients were not involved in the interpretation of results or writing of the article. The results will be disseminated to the lay audience through the authors' involvement with charities and through public presentations.

\section{Results}

We identified 406 potentially eligible studies that fulfilled the inclusion criteria of this review. ${ }^{512-1528-93}$ No unpublished studies were identified. We excluded studies without an untreated reference population, ${ }^{94-119}$ studies that included women treated during pregnancy, ${ }^{120} 121$ studies assessing fertility and early pregnancy outcomes below 24 weeks' gestation, ${ }^{122-127}$ studies assessing outcomes after treatment in high risk populations, ${ }^{128} 129$ and studies assessing the impact of CIN on outcomes without information as to whether treatment was performed. ${ }^{130-132}$ Figure 1 shows more details of the literature search and the reasons for exclusion. ${ }^{133}$

Table A in appendix 2 shows detailed characteristics of the included studies and the outcomes examined. Most studies were retrospective, with only five prospective reports. ${ }^{7177-82}$ All were cohort studies, apart from one 
case-control study by Castanon and colleagues. ${ }^{85}$ There were no randomised controlled studies. Fourteen studies examined the impact of cold knife conisation, $1328-3032-34$ 37 60-62828789 10 studied laser conisation, $424647-495152567678$ one studied needle excision of the transformation zone. ${ }^{13}$ 34 studied large loop excision of the transformation zone, ${ }^{1339-4144455055-60626365-69737476-8386-889091}$ eight studied laser ablation, 3538394749545662 one studied radical diathermy, ${ }^{62}$ two studied cryotherapy, ${ }^{3160} 16$ studied excision not otherwise specified, $5121415536470-72$ 75787984859093 five studied ablation not otherwise specified, ${ }^{1214537087}$ and three studied treatment not otherwise specified. ${ }^{364392}$ There were five types of untreated comparison groups. Some used an external comparator, ${ }^{51213-}$ $1528293335-4548-55$ 57-61 64-81 838687899293 others compared with the pregnancies before treatment in the treated population (internal) ${ }^{51530-323445-475873748491}$ or used self matching for women who delivered both before and after treatment (internal), ${ }^{13154348516466}$ some compared with women who underwent colposcopy with or without CIN and/or biopsy but had no treatment, ${ }^{15} 56626367687781-9193$ and some with women with high grade disease but no treatment. ${ }^{135370}$ All studies that used an external comparison group either matched for known risk factors or performed regression analysis to control for known confounders; four studies did not control for any confounders. 43616576

Table B in appendix 2 provides more details on the quality assessment for observational studies with the Newcastle-Ottawa score. Most studies scored 8 or 9 points, 10 scored $^{730354345-4750617276}$ and two scored $6 . .^{3865}$

\section{Maternal outcomes}

The risk of preterm birth was significantly increased after cervical treatment (table 1). For all treatment types, this was the case for overall prematurity at less than 37 weeks' gestation (relative risk 1.78, 95\% confidence interval 1.60 to 1.98 ), for severe prematurity less than 32-34 weeks' gestation (2.40, 1.92 to 2.99), and extreme prematurity less than 28-30 weeks' gestation (2.54, 1.77 to 3.63) (table 1). Figure 2 shows the risk asso-

Citations identified in literature search $(n=3021)$

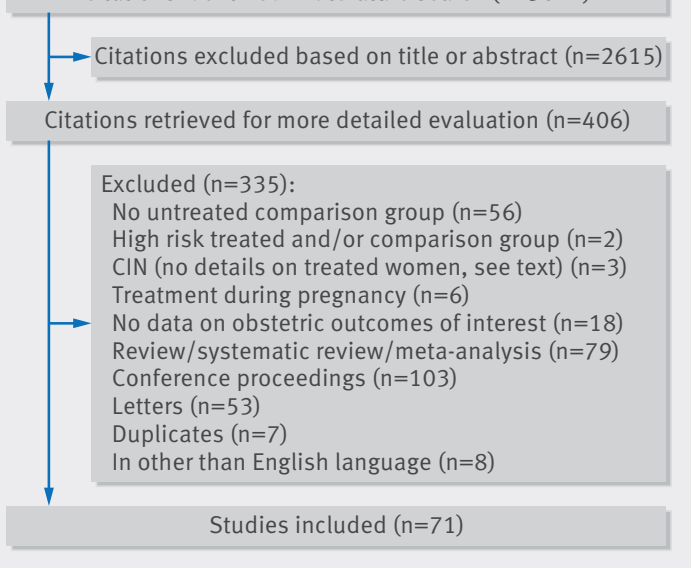

Fig 1 | Identification of studies to include in analysis of adverse obstetric outcomes after local treatment for cervical preinvasive and early invasive disease ciated with LLETZ versus no treatment. The forest plot in appendix 3 shows the risks for all treatment techniques versus no treatment. The magnitude of the effect of treatment was higher for more radical treatment techniques and for excision rather than ablation. More specifically, the risk of preterm birth at less than 37 weeks' gestation was higher for cold knife conisation (2.70, 2.14 to 3.40$)$, laser conisation $(2.11,1.26$ to 3.54$)$, excision not otherwise specified (2.02, 1.60 to 2.55), large loop excision of the transformation zone (1.56, 1.36 to 1.79 ), and ablation not otherwise specified (1.46, 1.27 to 1.66). Similar trends were noted for severe and extreme prematurity.

Treatment was also associated with an increased risk of preterm birth for women with multiple pregnancies for some but not all treatments (table C, appendix 2). Have asked author, but the results were inconsistent because of the small number of studies. The impact of treatment was no different for nulliparous and multiparous women (data not shown). The effect of multiple as opposed to single treatments on the risk of prematurity was substantially higher in comparisons with untreated women (relative risk 3.78 (95\% confidence interval 2.65 to 5.39) for repeated treatment and 1.75 (1.49 to 2.06) for single treatment, table 2). Compared with no treatment, the relative risk of preterm birth for two excisional treatments not otherwise specified was as high as 5.48 (2.68 to 11.24 ) and that of two loop excisions as high as 2.81 (2.33 to 3.39).

The analysis of the risk according to the cone dimensions showed that the risk increases progressively with increasing cone depth (table 3; fig 3) or cone volume (table 3). The risk for treated versus untreated women was significantly higher for women with cone depth $\leq 10-12 \mathrm{~mm}$ (relative risk 1.54, 95\% confidence interval 1.09 to 2.18). The magnitude of effect increased with increasing cone depth (1.93 (1.62 to 2.31) for $\geq 10-12 \mathrm{~mm}$, 2.77 (1.95 to 3.93) for $\geq 15-17 \mathrm{~mm}$, and 4.91 (2.06 to 11.68) for $\geq 20 \mathrm{~mm}$; table 3 ). The trend was similar with increasing cone volume (2.25 (1.09 to 4.66) for $\leq 6 \mathrm{cc}$ and 13.9 ( 5.09 to 37.98 ) for $\geq 6 \mathrm{cc}$; table 3 ). Further analyses of the individual cone depth cut offs not grouped together showed similar results (data not shown).

The comparison of women treated with different cone depths showed that deeper excisions significantly increased the risk of preterm birth compared with less deep excisions, and the magnitude of the effect increased in deeper cones. The relative risk were 1.54 (95\% confidence interval 1.31 to 1.80 ) for $\geq 10-12 \mathrm{~mm} v$ $\leq 10-12 \mathrm{~mm}, 1.82$ (1.47 to 2.26 ) for $\geq 15-17 \mathrm{~mm} v \leq 15-17 \mathrm{~mm}$, and 1.82 (1.47 to 2.26) for $\geq 20 \mathrm{~mm} v \leq 20 \mathrm{~mm}$ (fig 4). Full data are also provided in table $\mathrm{D}$, appendix 2 . The findings were similar for the comparison of cone volumes (2.04 (0.95 to 4.39) for $\geq 3-4$ cc $v \leq 3-4$ cc (15.0\% $v 7.3 \%$, one study, 278 women); 6.18 (2.53 to 15.13) for $\geq 6$ cc $v \leq 6 \mathrm{cc}$ (50.0\% v 8.1\%, one study, 278 women).

We assessed the impact that the choice of comparison group can have on the magnitude of effect in a subgroup analysis that classified different studies according to the comparator used (table 4). The results suggested that treatment significantly increased the 


\begin{tabular}{|c|c|c|c|c|c|c|}
\hline \multirow[b]{2}{*}{ Preterm birth } & \multirow[b]{2}{*}{ No of studies } & \multirow{2}{*}{$\begin{array}{l}\text { Total No of } \\
\text { women }\end{array}$} & \multicolumn{2}{|l|}{ No (\%) of women } & \multirow{2}{*}{$\begin{array}{l}\text { Effect estimate RR } \\
(95 \% \mathrm{Cl})\end{array}$} & \multirow{2}{*}{$\begin{array}{l}\text { P value for } \\
\text { heterogeneity (12\%) }\end{array}$} \\
\hline & & & Treated & Untreated & & \\
\hline \multicolumn{7}{|l|}{$<37$ weeks' gestation } \\
\hline All treatment types & 60 & 5244560 & $6506 / 60619(10.7)$ & $281575 / 5183941(5.4)$ & $1.78(1.60$ to 1.98$)$ & $<0.001(88)$ \\
\hline CKC & 12 & 39102 & $126 / 844(14.9)$ & $2321 / 38258(6.1)$ & $2.70(2.14$ to 3.40$)$ & $0.62(0)$ \\
\hline LC & 9 & 1464 & $96 / 672(14.3)$ & $58 / 792(7.3)$ & 2.11 (1.24 to 3.57$)$ & $0.02(56)$ \\
\hline NETZ & 1 & 7399 & $17 / 71(23.9)$ & $301 / 7328(4.1)$ & 5.83 (3.80 to 8.95$)$ & $\mathrm{N} / \mathrm{E}$ \\
\hline LLETZ & 26 & 1445341 & $1724 / 21318(8.1)$ & $66607 / 1424023(4.7)$ & 1.56 (1.36 to 1.79$)$ & $<0.001(69)$ \\
\hline LA & 7 & 4710 & $168 / 1867(9.0)$ & $242 / 2843(8.5)$ & $1.04(0.86$ to 1.26$)$ & $0.48(0)$ \\
\hline $\mathrm{CT}$ & 2 & 238 & 4/151 (2.6) & $2 / 87(2.3)$ & $1.02(0.22$ to 4.77$)$ & $0.67(0)$ \\
\hline $\mathrm{RD}$ & 1 & 2150 & 109/760 (14.3) & $123 / 1390(8.8)$ & $1.62(1.27$ to 2.06$)$ & N/E \\
\hline Excisional treatment NOS & 15 & 3107438 & $3788 / 28104(13.4)$ & $183133 / 3079334$ (5.9) & 2.02 (1.60 to 2.55$)$ & $<0.001(95)$ \\
\hline Ablative treatment NOS & 5 & 595272 & $430 / 6482(6.6)$ & $26804 / 588790(4.6)$ & $1.46(1.27$ to 1.66$)$ & $0.22(30)$ \\
\hline Treatment NOS & 3 & 41401 & $44 / 350(12.6)$ & $1979 / 41051(4.8)$ & 2.20 (1.28 to 3.78$)$ & $0.07(62)$ \\
\hline \multicolumn{7}{|l|}{$<32-34$ weeks' gestation } \\
\hline All treatment types & 25 & 3795351 & 1375/39647 (3.5) & $53835 / 3755704(1.4)$ & 2.40 (1.92 to 2.99$)$ & $<0.001(82)$ \\
\hline CKC & 5 & 36979 & $15 / 283(5.3)$ & $920 / 36696(2.5)$ & 3.07 (1.72 to 5.49$)$ & $0.65(0)$ \\
\hline NETZ & 1 & 7399 & $5 / 71(7.0)$ & 49/7328 (0.7) & $10.53(4.33$ to 25.65$)$ & $\mathrm{N} / \mathrm{E}$ \\
\hline LLETZ & 11 & 791554 & $237 / 11569(2.0)$ & $9504 / 779985(1.2)$ & 2.13 (1.66 to 2.75$)$ & $0.08(40)$ \\
\hline CT & 1 & 58 & $1 / 36(2.8)$ & $0 / 22(0.0)$ & 1.86 (0.08 to 43.87) & N/E \\
\hline Excisional treatment NOS & 10 & 2832112 & $1000 / 22562(4.4)$ & $42598 / 2809550(1.5)$ & 3.05 (1.95 to 4.78$)$ & $<0.001(91)$ \\
\hline Ablative treatment NOS & 2 & 120762 & $26 / 2549(1.0)$ & $686 / 118213(0.6)$ & 1.59 (1.08 to 2.35$)$ & $0.92(0)$ \\
\hline Treatment NOS & 2 & 6487 & $91 / 2577(3.5)$ & $78 / 3910(2.0)$ & 1.65 (1.13 to 2.42$)$ & $0.25(24)$ \\
\hline \multicolumn{7}{|l|}{$<28-30$ weeks' gestation } \\
\hline All treatment types & 9 & 3912106 & 403/39154 (1.0) & $12887 / 3872952(0.3)$ & 2.54 (1.77 to 3.63$)$ & $<0.001(81)$ \\
\hline CKC & 2 & 7118 & $2 / 150(1.3)$ & $19 / 6968(0.3)$ & $4.52(0.83$ to 24.54$)$ & $0.74(0)$ \\
\hline NETZ & 1 & 7399 & $3 / 71(4.2)$ & $21 / 7328(0.3)$ & $14.74(4.50$ to 48.32$)$ & $\mathrm{N} / \mathrm{E}$ \\
\hline LLETZ & 3 & 502778 & $59 / 8899(0.7)$ & $1224 / 493879(0.2)$ & 2.57 (1.97 to 3.35$)$ & $0.9(0)$ \\
\hline Excisional treatment NOS & 4 & 2821185 & $287 / 21984(1.3)$ & $9854 / 2799201(0.4)$ & $2.90(1.52$ to 5.52$)$ & $<0.001(88)$ \\
\hline Ablative treatment NOS & 3 & 568217 & $23 / 6125(0.4)$ & $1739 / 562092(0.3)$ & 1.38 (0.81 to 2.36$)$ & $0.21(35)$ \\
\hline Treatment NOS & 1 & 5409 & $29 / 1925$ & $30 / 3484$ & 1.75 (1.05 to 2.91$)$ & $\mathrm{N} / \mathrm{E}$ \\
\hline
\end{tabular}

risk of preterm birth at less than 37 weeks' gestation irrespective of the comparison group used. The magnitude of effect was higher when an external comparison group was used (relative risk 1.93, 95\% confidence interval 1.71 to 2.17 ), followed by internal comparators (1.52 (1.17 to 1.97) for self matching and 1.42 (1.01 to 1.99) for pregnancies before treatment), and ultimately women with disease but no treatment (1.27, 1.14 to 1.41$)$. In women with untreated CIN, and in pregnancies before treatment, the risk of preterm birth compared with general population was significantly higher $(1.24,1.14$ to 1.35). The subgroup analysis of the risk of preterm birth according to cone depth and comparison group showed a similar direction of effect, although for cone depth $\leq 10$ $12 \mathrm{~mm}$ the difference became insignificant. The number of studies was small for many comparisons. For treated versus untreated women with CIN there were four studies for cone depth $\leq 10-12 \mathrm{~mm}$ (43145 women, $7.0 \% \mathrm{v}$ $5.0 \%$, relative risk $1.11,95 \%$ confidence interval 0.85 to 1.43), four studies for cone depth $\geq 10-12 \mathrm{~mm}$ (45275 women, $9.6 \% v 5.0 \%, 1.52,1.37$ to 1.68 ), three studies for cone depth $\geq 15-17 \mathrm{~mm}$ (33934 women, 9.6\% v 4.3\%, 2.30, 1.57 to 3.35), and two studies for cone depth $\geq 20 \mathrm{~mm}$ (32717 women, 9.3\% v 4.2\%, 4.32, 0.93 to 20.03) (table E, appendix 2). Furthermore, the sensitivity analysis that excluded studies that scored below the median Newcastle-Ottawa score (8.3) did not change the results of the analysis; similarly the results did not change when we excluded studies that scored $\leq 7$ and $\leq 6$ (data not shown). The subgroup analyses of studies based on the cohort selection or the comparability of the comparison groups showed similar direction and magnitude of effect (data not shown). The univariate meta-regression analysis suggested that the type of treatment and comparator significantly affected the risk of preterm birth, although the type of treatment and Newcastle-Ottawa score did not. These factors remained significant in a multivariate regression analysis. When we performed further meta-regression restricting only to excisional treatments and using as a comparator women with colposcopy/ biopsy, we found that all treatments were associated with an increased risk of preterm birth $(1.34,1.10$ to 1.64 , for large loop excision of the transformation zone; 2.3, 1.39, 3.85, for cold knife conisation; 1.6, 0.91 to 2.87 , for laser conisation; and 4.26, 1.96 to 9.33 , for needle excision of the transformation zone).

Several studies assessed other adverse maternal outcomes (table F, appendix 2), and many of these were found to be increased after cervical treatment. This increase was more commonly associated with 
Study

Gunasekera 1992

Blomfield 1993

Haffenden 1993

Braet 1994

Cruickshank 1995

Paraskevaidis 2002

Sadler 2004

Tan 2004

Samson 2005

Acharya 2005

Crane 2006

Himes 2007

Bruinsma 2007

Noehr 2009 (singletons and cone depth) 530/8180

Werner 2010

Ortoft 2010

Andia 2011

Lima 2011

Simoens 2012

Poon 2012

Frega 2013

Heinonen 2013

Frey 2013

Guo 2013

Martyn 2015

Stout 2015

Total $(95 \% \mathrm{Cl})$

Test for heterogeneity: $\tau^{2}=0.05, \chi^{2}=78.52, \mathrm{df}=24, \mathrm{P}<0.001, \mathrm{I}^{2}=69 \%$

Test for overall effect: $z=6.38, P<0.001$

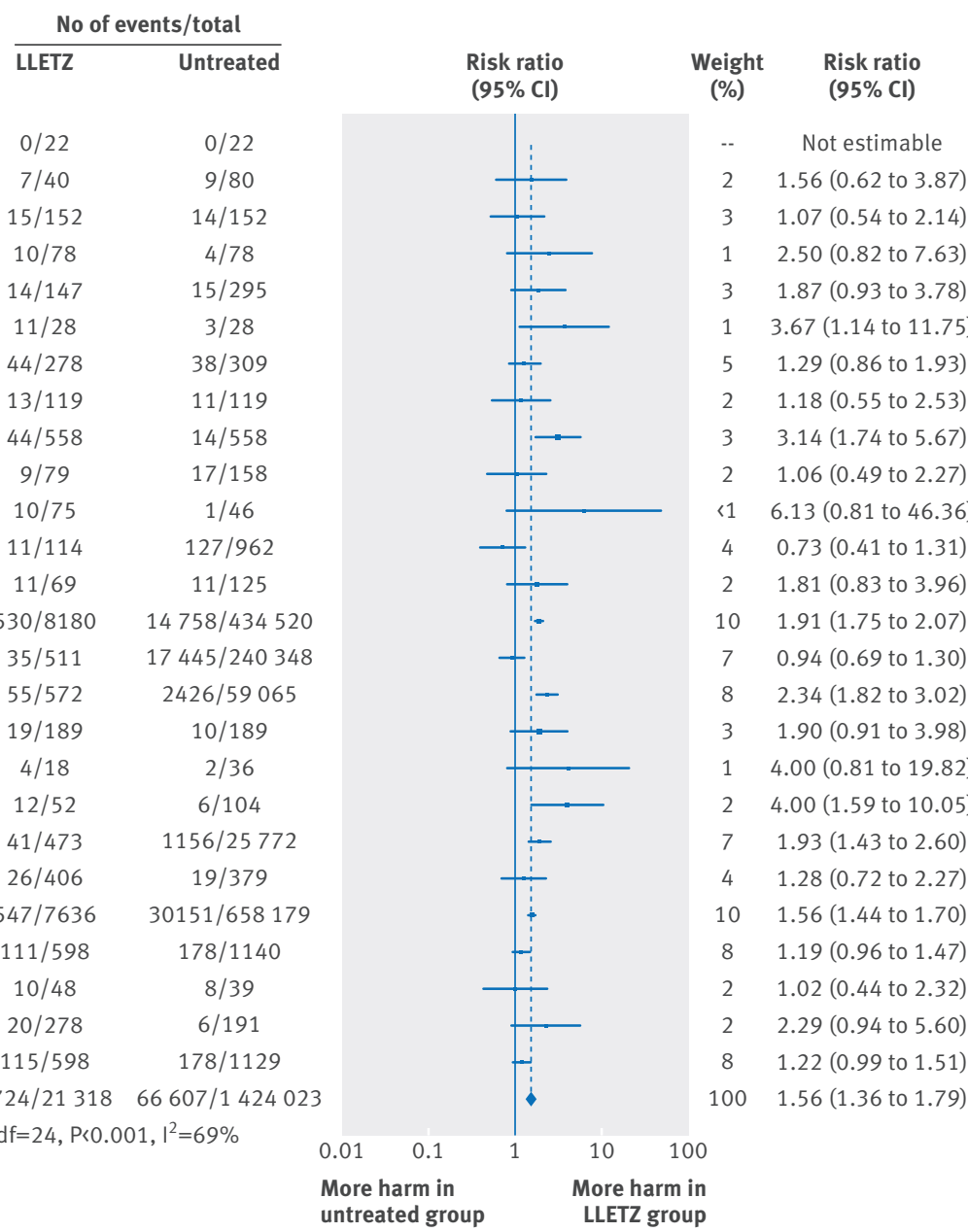

Fig 2 | Meta-analysis of studies on preterm birth ( $<37$ weeks) in women treated with large loop excision of transformation zone versus untreated women

excisional than ablative techniques and with more radical treatment, although the number of studies assessing each individual treatment method was often small. Cervical treatment was associated with an increased risk of spontaneous overall, severe, and extreme preterm birth (<37 weeks: 14 studies, 1024731 women, $7.0 \%$ v 3.7\%; relative risk $1.76,95 \%$ confidence interval 1.47 to 2.11 ; <32-34 weeks: seven studies, 655675 women, $1.8 \%$ v $0.6 \%$; 2.63, 1.91 to 3.62 ; <28 weeks: two studies, 626670 women, $0.6 \% v 0.2 \%, 3.18,1.64$ to 6.16 ) and admissions for threatened preterm birth (five studies, 903 women, $9.1 \% v 3.2 \%, 2.44,1.37$ to 4.33$)$. The risk ( $<37$ weeks) was higher for cold knife conisation (3.53, 2.05 to 6.05) followed by excision not otherwise specified (1.70, 1.17 to 2.46), large loop excision of the transformation zone $(1.60,1.22$ to 2.08$)$, and ablation not otherwise specified (1.42, 1.20 to 1.70). Needle excision of the transformation zone and laser ablation were each assessed in only one study. There was substantial heterogeneity for the comparisons assessing all gestational categories $(\mathrm{P}<0.05)$.

The risk of premature rupture of membranes $(<37$ weeks: 21 studies, 477011 women; 6.1\% v 3.4\%, relative risk $2.36,95 \%$ confidence interval 1.76 to 3.17 ) and chorioamnionitis (four studies, 29198 women, 3.5 v 1.1\%;
3.43, 1.36 to 8.64 ) was also increased after treatment. Risk was higher after cold knife conisation (4.11, 2.05 to 8.25) followed by large loop excision of the transformation zone $(2.15,1.48$ to 3.12$)$. Needle excision of the transformation zone was assessed in only one study, and laser ablation did not significantly affect the risk but was assessed in only two studies.

The mode of delivery (caesarean section or instrumental delivery), the length of labour (precipitous or prolonged), the use of analgesia (epidural, pethidine, or other), the rate of induction of labour (with or without oxytocin), cervical stenosis, and haemorrhage (antenatal or postpartum) were not affected by treatment. As expected, the rate of cervical cerclage insertion was higher for treated than non-treated women (eight studies, 141300 women, $4.0 \% v 0.7 \%$, relative risk 14.29 , $95 \%$ confidence interval 2.85 to 71.65 ) and more so for cold knife conisation (31.42, 2.32 to 426.2), large loop excision of the transformation zone (11.0, 0.64 to 190), or excisional treatment not otherwise specified (42.45, 28.99 to 62.16).

\section{Neonatal outcomes}

More than 30 studies assessed one or more neonatal outcomes (table G, appendix 2). Cervical treatment (excisional or ablative) was associated with a significant 


\begin{tabular}{|c|c|c|c|c|c|c|}
\hline & \multirow[b]{2}{*}{ No of studies } & \multirow{2}{*}{$\begin{array}{l}\text { Total No of } \\
\text { women }\end{array}$} & \multicolumn{2}{|l|}{ No (\%) of women } & \multirow{2}{*}{$\begin{array}{l}\text { Effect estimate RR } \\
(95 \% \mathrm{CI})\end{array}$} & \multirow{2}{*}{$\begin{array}{l}\text { P value for } \\
\text { heterogeneity (12\%) }\end{array}$} \\
\hline & & & Treated & Untreated & & \\
\hline \multicolumn{7}{|l|}{ Single treatment } \\
\hline All treatment types & 17 & 1367023 & $1519 / 20302(7.5)$ & $56185 / 1346721(4.2)$ & 1.75 (1.49 to 2.06$)$ & $<0.001(79)$ \\
\hline CKC & 3 & 36783 & $38 / 179(21.2)$ & $2250 / 36604(6.1)$ & 2.89 (2.08 to 4.03$)$ & $0.42(0)$ \\
\hline LC & 2 & 657 & $34 / 335(10.1)$ & $29 / 322(9.0)$ & 1.06 (0.54 to 2.09) & $0.17(48)$ \\
\hline NETZ & 1 & 7399 & $17 / 71(23.9)$ & $301 / 7328(4.1)$ & 5.83 (3.80 to 8.95$)$ & N/E \\
\hline LLETZ & 9 & 1277874 & $1139 / 16755(6.8)$ & $51075 / 1261119(4.0)$ & 1.74 (1.45 to 2.10$)$ & $<0.001(75)$ \\
\hline LA & 4 & 1421 & $58 / 624(9.3)$ & $68 / 797(8.5)$ & 1.07 (0.66 to 1.74$)$ & $0.17(40)$ \\
\hline Excisional treatment NOS & 3 & 32106 & 197/1816 (10.8) & $1840 / 30290(6.1)$ & 1.88 (1.20 to 2.93$)$ & $0.1(57)$ \\
\hline Ablative treatment NOS & 1 & 10783 & $36 / 522(6.9)$ & $622 / 10261(6.1)$ & 1.14 (0.82 to 1.57) & $\mathrm{N} / \mathrm{E}$ \\
\hline \multicolumn{7}{|l|}{ Repeat treatment } \\
\hline All treatment types & 11 & 1317284 & $191 / 1442(13.2)$ & $54142 / 1315842(4.1)$ & 3.78 (2.65 to 5.39$)$ & $<0.001(75)$ \\
\hline CKC/LA & 1 & 99 & $2 / 2(100.0)$ & $6 / 97(6.2)$ & 12.56 (5.11 to 30.87$)$ & $N / E$ \\
\hline $\mathrm{LC} / \mathrm{LC}$ & 1 & 270 & $6 / 20(30.0)$ & $20 / 250(8.0)$ & 3.75 (1.70 to 8.27$)$ & $\mathrm{N} / \mathrm{E}$ \\
\hline LLETZ/LLETZ & 4 & 1202174 & 139/1195 (11.6) & $48586 / 1200979(4.0)$ & 2.81 (2.33 to 3.39$)$ & $0.35(9)$ \\
\hline LLETZ/treatment NOS & 1 & 298 & $9 / 41(22.0)$ & $6 / 257(2.3)$ & $9.40(3.53$ to 25.03$)$ & $\mathrm{N} / \mathrm{E}$ \\
\hline $\begin{array}{l}\text { Excisional NOS/excisional } \\
\text { treatment NOS }\end{array}$ & 3 & 73651 & $17 / 57(29.8)$ & $3034 / 73594$ (4.1) & 5.48 (2.68 to 11.24$)$ & $0.16(45)$ \\
\hline $\begin{array}{l}\text { Treatment NOS/treatment } \\
\text { NOS }\end{array}$ & 2 & 40792 & $18 / 127(14.2)$ & $2490 / 40665$ (6.1) & 1.71 (1.10 to 2.67) & $0.85(0)$ \\
\hline
\end{tabular}

increase in adverse neonatal outcomes compared with outcomes in women who did not undergo treatment (comparison group not specified). The association with adverse neonatal events was stronger and more common for excisional rather than ablative techniques and with increasing treatment radicality, although the number of studies for each individual treatment technique was often limited.

More specifically, cervical treatment overall was associated with an increased risk of low birth weight (<2500 g: 30 studies, 1348206 women, $7.9 \%$ v 3.7\%, relative risk 1.81, 95\% confidence interval 1.58 to 2.07; $<1500$ g: five studies, 76836 women, $2.0 \% v 0.5 \%$, 3.00, 1.54 to 5.85 ), admission to a neonatal intensive unit (eight studies, 2557 women, $12.6 \% v 8.9 \%, 1.45,1.16$ to 1.81), and perinatal mortality (23 studies, 1659433 women, $0.9 \% v 0.7 \%, 1.51,1.13$ to 2.03$)$. There was significant heterogeneity between studies for perinatal mortality $\left(\mathrm{P}=0.04, \mathrm{I}^{2}=36 \%\right)$.

The rate of neonates with birth weight $<2500$ g was significantly higher for women treated with cold knife conisation (five studies, 30304, relative risk 2.51, 95\% confidence interval 1.78 to 3.53), large loop excision of the transformation zone (12 studies, 3357, 2.11, 1.51 to 2.94), excisional (10 studies, 823648, 2.01, 1.62 to 2.49 ) or ablative (four studies, 483402, 1.36, 1.19 to 1.55 ) treatment not otherwise specified but not so for laser ablation (1.07, 0.59 to 1.92), although for that comparison there were only four studies with a total of 1104 participants. The rate of admission to neonatal intensive care was assessed only for excisional techniques and was significantly increased after large loop excision of the transformation zone (five studies, 1994 women, 1.42, 1.01 to 1.99). Perinatal mortality was significantly increased overall and for excisional technique not otherwise specified (five studies, 820028 ,
1.85, 1.02 to 3.36) but not for the individual techniques, possibly because of the limited number of studies and the low prevalence of the outcome. Subgroup analysis according to the different comparison groups or cone depths was not possible because of the limited number of studies assessing each outcome.

\section{Discussion}

\section{Main findings}

The knowledge that local treatment for cervical precancer, particularly excisional, increases the risk of preterm birth has led to major changes in clinical practice. With a rapidly evolving evidence base and inconsistencies in the published literature, ${ }^{141517} 1866113$ a high quality synthesis of the evidence should be available for effective counselling of patients at colposcopy and antenatal clinics.

This meta-analysis shows that any local cervical treatment for preinvasive or early invasive disease increases the risk of preterm birth and adverse sequelae in a subsequent pregnancy, although the impact of small excisions, as opposed to just having the disease, remains uncertain and is likely to be small. Cervical treatment was found to be associated with an increased risk of overall, severe, and extreme prematurity, spontaneous preterm birth, threatened preterm labour, premature rupture of the membranes, chorioamnionitis, low birth weight, neonatal admission, and perinatal death. The rate of cervical cerclage was unsurprisingly substantially increased in treated women compared with untreated controls. Treatment equally affected outcomes for nulliparous as well as parous women and singleton and multiple pregnancies. The mode of delivery, length of labour, induction rate, use of analgesia, rate of stenosis, and haemorrhage were not significantly affected. 
Table 3 | Preterm birth (<37 weeks' gestation) in women with cervical intraepithelial neoplasia (CIN) for treated versus untreated women according to cone depth and volume

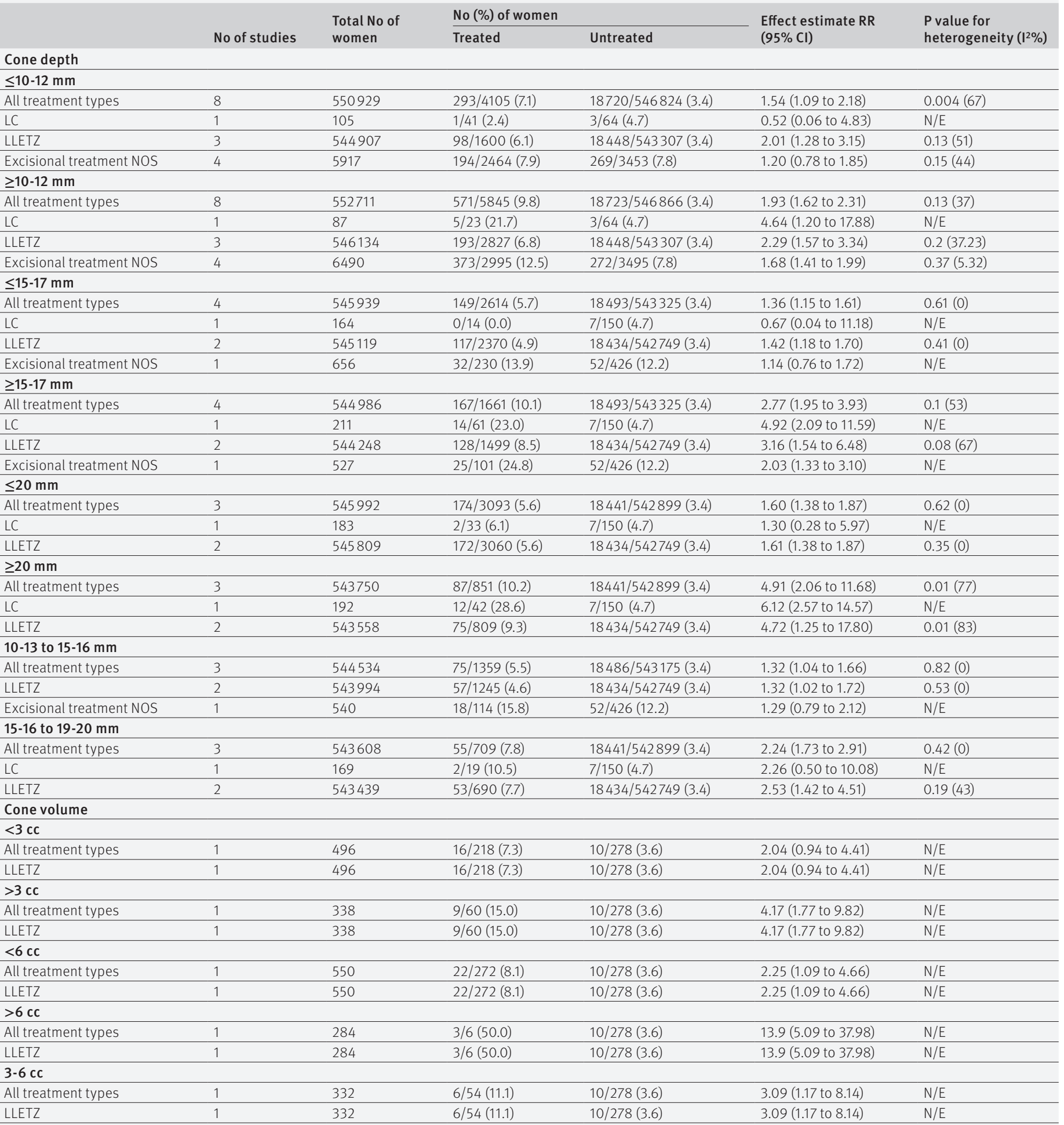

LC=laser conisation; LLETZ=large loop excision of transformation zone; N/E=not eligible; NETZ=needle excision of transformation zone; NOS=not otherwise specified.

*In cases of heterogeneity in cut offs used for classification of cone depth, these were grouped together when possible (for instance, 10-12 mm in depth included studies using either cut off $\geq 11-12$ or $\leq 11-12 \mathrm{~mm}$ as some studies included depths equal to cut off and others did not).

The magnitude of the effect of treatment was higher for more radical techniques (such as cold knife conisation followed by large loop excision of the transformation zone and laser ablation) and for excision rather than ablation. Multiple conisations increased the risk of preterm birth fourfold compared with untreated con- trols overall. Subgroup analyses clearly showed that the risk of preterm birth is directly correlated with the cone dimensions (depth/volume) and progressively increases with increasing cone depth ("dose effect"). Although the risk was increased even for excisions less than $10 \mathrm{~mm}$ in depth, this was almost twofold for excisions of more 


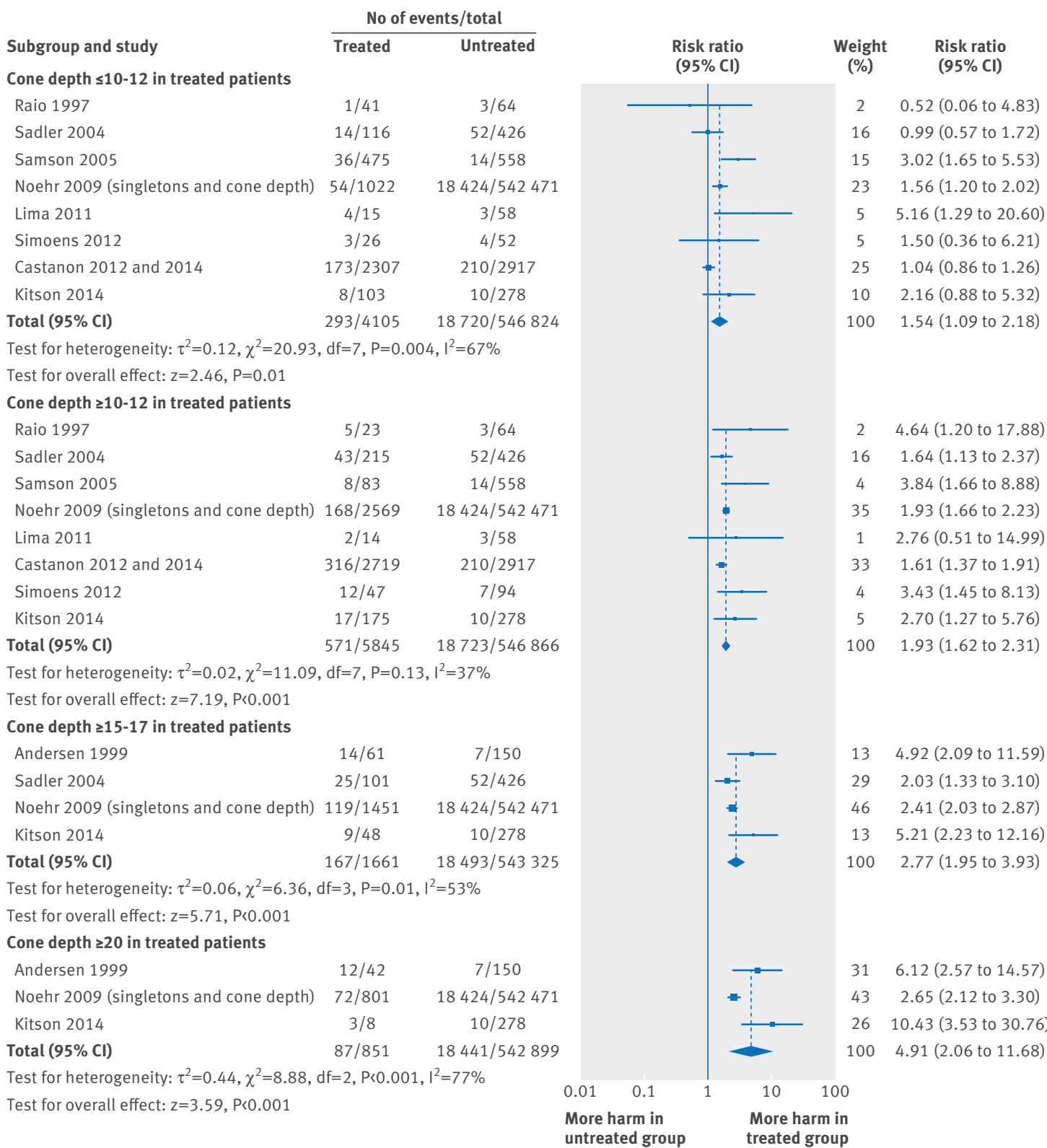

Fig 3 | Preterm birth (<37 weeks) in women treated for CIN according to cone depth ( $\leq 10-12 \mathrm{~mm}, \geq 10-12 \mathrm{~mm}, \geq 15-17 \mathrm{~mm}$, $\geq 20 \mathrm{~mm}$ ) versus untreated women

than $10 \mathrm{~mm}$, threefold for more than $15-17 \mathrm{~mm}$, and almost fivefold for excisions exceeding $20 \mathrm{~mm}$ in depth.

It has previously been suggested that the impact of treatment on the risk of preterm birth might not be a consequence of treatment but rather a product of other confounders present in women with cervical disease. ${ }^{71415}$ Our subgroup analyses that stratified the risk by the comparator used, clearly documents that although the risk of preterm birth is significantly increased after treatment irrespective of the comparison group used, the choice of comparator might overinflate or underestimate the effect from treatment. The magnitude of effect was higher when we used external controls, followed by internal controls, followed by women who had disease but were not treated. The analyses in women with high grade squamous intraepithelial lesion but no treatment only included three studies and 3764 participants; we were unable to draw any firm conclusions from this comparison. When we assessed the risk of preterm birth according to both the cone depth and comparator, we noted overall the same direction of effect. Although the difference in the risk of preterm birth for small excisions ( $\leq 10-12 \mathrm{~mm}$ ) compared with just having CIN but no treatment, became insignificant, the number of studies assessing that comparison was small, and we cannot draw firm conclusions.

Our results also confirm that although women with CIN have a higher baseline risk of prematurity than the general population, cervical treatment, and particularly deep cones, further increase that risk.

\section{Strengths and limitations}

This is the first systematic review to show that any local cervical treatment technique (excisional or destructive) 


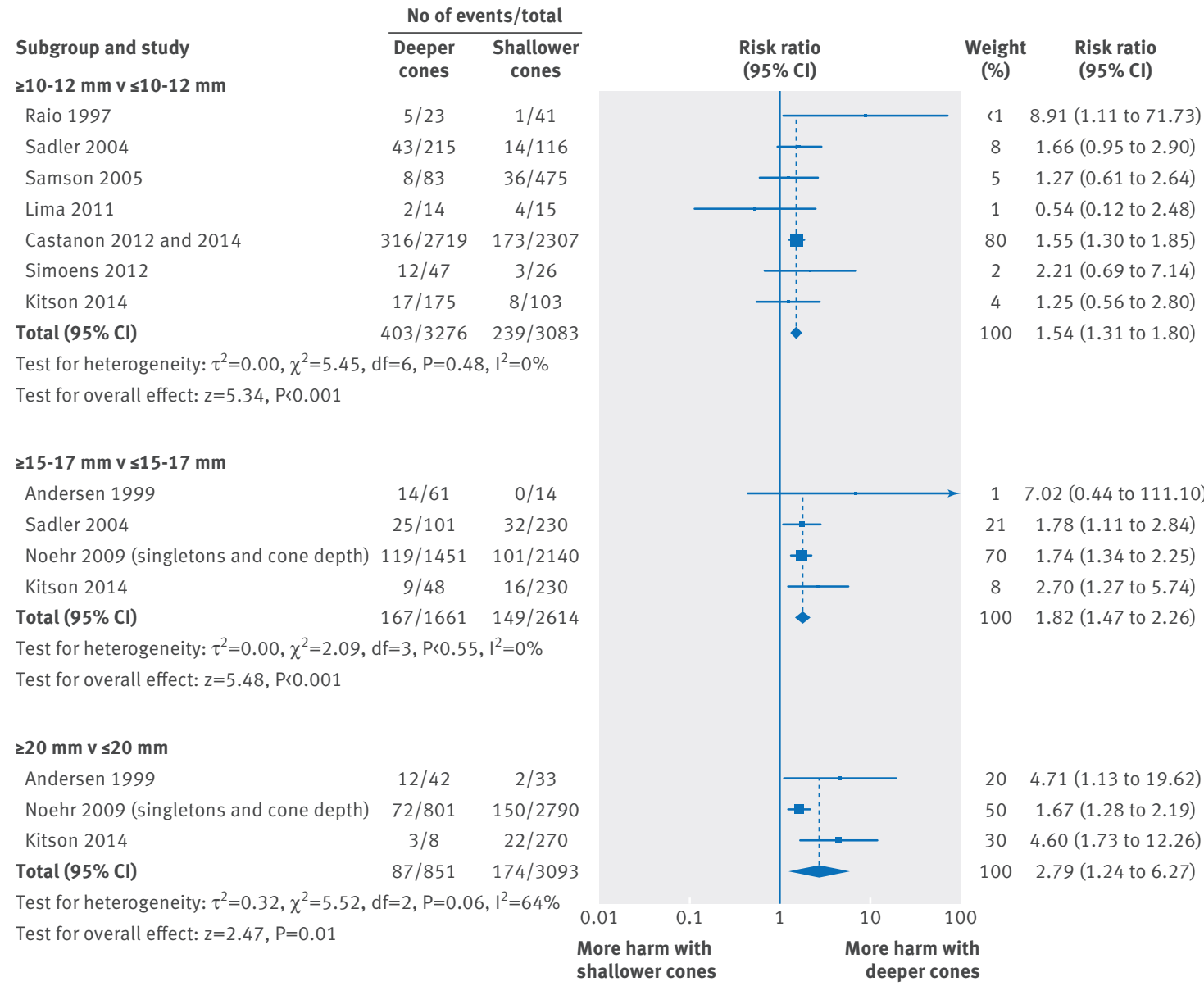

Fig 4 | Preterm birth ( $<37$ weeks' gestation) in women treated for CIN according to cone depth

is associated with an increased risk of preterm birth and adverse obstetric sequelae and to document that the risk directly correlates to the cone depth (and volume), the treatment technique (excision more than ablation), and radicality. This meta-analysis included a large number of studies (71 cohorts) with sufficient sample size and power to explore several comparisons of treatment techniques and cone depths. Furthermore, we were able to perform subgroup analyses according to the comparator used and quantify the risk in different clinical groups.

The results, however, should be interpreted with caution. Because of the premalignant nature of the disease, no randomised studies could be identified. All the included studies were cohorts, nearly all retrospective. Such reports are at known risk of recall bias and inadequate adjustment for known and unknown confounders, while some of the outcomes of interest were difficult to measure objectively. Many of the studies relied on data collected from structured interviews and mailed questionnaires, and in some of these the response rate was small, also increasing the risk of incomplete outcome data (attrition) and misclassification bias. The studies often had different designs and used comparisons between and among women and mixed matching. Although the overall number of studies was large, for some outcomes and comparisons there were few stud- ies, and the analyses did not have sufficient sample sizes to support definite conclusions.

Although heterogeneity between studies was not significant for most of the analyses, some subgroup analyses did show variation in the outcomes across studies. This was often in analyses that included small number of studies and participants. Meta-regression was possible for some but not all possible confounders. For many moderators, data were reported only in a proportion of the included studies. When these studies were not deemed representative of the whole population of studies, we did not perform meta-regression as this would introduce bias. Sensitivity and subgroups analyses based on study quality did not change the effect of the meta-analysis.

There were further limitations in the interpretation of the data. The gestational age cut offs used for the definitions of severe and extreme prematurity and for different cone depths varied slightly across studies; we merged these in broader groups for the analysis. Individual patient meta-analysis data are required to more accurately describe the stratified risk of preterm birth for individual cone depths. The data on cone dimensions relied on retrospective data recorded in histopathology reports of formalin fixed samples, with obvious limitations. The formulas used for the calculation of volume also varied across studies. Future research 
Table 4 | Preterm birth (<37 weeks' gestation) in women with cervical intraepithelial neoplasia (CIN) for treated and untreated women according to comparison group

\begin{tabular}{|c|c|c|c|c|c|c|}
\hline \multirow[b]{2}{*}{ Comparison } & \multirow[b]{2}{*}{ No of studies } & \multirow{2}{*}{$\begin{array}{l}\text { Total No of } \\
\text { women }\end{array}$} & \multicolumn{2}{|l|}{ No (\%) of women } & \multirow{2}{*}{$\begin{array}{l}\text { Effect estimate RR } \\
(95 \% \mathrm{Cl})\end{array}$} & \multirow{2}{*}{$\begin{array}{l}\text { P value for } \\
\text { heterogeneity ( } 12 \%)\end{array}$} \\
\hline & & & Treated & Untreated & & \\
\hline \multicolumn{7}{|c|}{ All treatment types $v$ untreated external } \\
\hline Overall & 46 & 5193761 & $5888 / 55799(10.6)$ & $278963 / 5137962(5.4)$ & $1.93(1.71$ to 2.17$)$ & $<0.001(90)$ \\
\hline CKC & 7 & 37370 & $62 / 390(15.9)$ & $2263 / 36980(6.1)$ & 3.28 (2.44 to 4.42$)$ & $0.99(0)$ \\
\hline LC & 6 & 1126 & $68 / 480(14.2)$ & 46/646 (7.1) & $2.39(1.24$ to 4.61$)$ & $0.02(63)$ \\
\hline NETZ & 1 & 7361 & $17 / 71(23.9)$ & $300 / 7290(4.1)$ & $5.82(3.79$ to 8.94$)$ & $\mathrm{N} / \mathrm{E}$ \\
\hline LLETZ & 20 & 1415006 & 1513/19934 (7.6) & $65080 / 1395072(4.7)$ & 1.69 (1.46 to 1.97$)$ & $<0.001(68)$ \\
\hline LA & 4 & 1258 & $37 / 510(7.3)$ & $50 / 748(6.7)$ & $1.27(0.67$ to 2.4$)$ & $0.19(38)$ \\
\hline CT & 1 & 58 & $1 / 36(2.8)$ & $0 / 22(0.0)$ & 1.86 (0.08 to 43.87) & N/E \\
\hline Excision NOS & 12 & 3101232 & $3716 / 27546(13.5)$ & $182711 / 3073686$ (5.9) & 2.05 (1.61 to 2.60$)$ & $<0.001(96)$ \\
\hline Ablation NOS & 5 & 588949 & $430 / 6482(6.6)$ & $26534 / 582467(4.6)$ & $1.45(1.26$ to 1.67$)$ & $0.19(35)$ \\
\hline Treatment NOS & 3 & 41401 & 44/350 (12.6) & $1979 / 41051(4.8)$ & 2.20 (1.28 to 3.78$)$ & $0.07(62)$ \\
\hline \multicolumn{7}{|c|}{ All treatment types $v$ internal (pre-treatment pregnancies) } \\
\hline Overall & 14 & 83528 & $3117 / 22121$ (14.1) & $3949 / 61407(6.4)$ & $1.42(1.01$ to 1.99$)$ & $<0.001(89)$ \\
\hline CKC & 3 & 1430 & $39 / 347(11.2)$ & $38 / 1083(3.5)$ & 1.79 (0.81 to 3.95$)$ & $0.15(47)$ \\
\hline LC & 2 & 161 & $8 / 87(9.2)$ & $3 / 74(4.1)$ & 1.65 (0.11 to 23.58$)$ & $0.06(7)$ \\
\hline LLETZ & 5 & 3331 & 192/1524 (12.6) & $178 / 1807(9.9)$ & $1.21(0.73$ to 2.01$)$ & $0.002(77)$ \\
\hline LA & 1 & 226 & $16 / 129(12.4)$ & 10/97 (10.3) & 1.20 (0.57 to 2.53$)$ & $\mathrm{N} / \mathrm{E}$ \\
\hline CT & 1 & 180 & $3 / 115(2.6)$ & $2 / 65(3.1)$ & $0.85(0.15$ to 4.94$)$ & N/E \\
\hline Excision NOS & 3 & 78200 & $2859 / 19919(14.3)$ & $3718 / 58281(6.4)$ & 1.65 (0.88 to 3.08$)$ & $<0.001(96)$ \\
\hline \multicolumn{7}{|c|}{ All treatment types $v$ internal (self matching) } \\
\hline Overall & 7 & 2916 & $157 / 1458(10.8)$ & $103 / 1458(7.1)$ & $1.52(1.17$ to 1.97$)$ & $0.36(9)$ \\
\hline LC & 2 & 354 & $12 / 177(6.8)$ & $9 / 177(5.1)$ & $1.30(0.56$ to 3.06$)$ & $0.42(0)$ \\
\hline LLETZ & 1 & 516 & $31 / 258(12.0)$ & $17 / 258(6.6)$ & $1.82(1.04$ to 3.21$)$ & N/E \\
\hline Excision NOS & 3 & 1922 & 104/961 (10.8) & $72 / 961(7.5)$ & 1.46 (0.89 to 2.39$)$ & $0.08(60)$ \\
\hline Treatment NOS & 1 & 124 & $10 / 62(16.1)$ & $5 / 62(8.1)$ & $2.00(0.73$ to 5.51$)$ & $\mathrm{N} / \mathrm{E}$ \\
\hline \multicolumn{7}{|c|}{ All treatment types $v$ untreated colposcopy+/-biopsy } \\
\hline Overall & 13 & 74958 & $2033 / 23123(8.8)$ & $3119 / 51835(6.0)$ & $1.27(1.14$ to 1.41$)$ & $<0.001(55)$ \\
\hline CKC & 2 & 265 & $25 / 107(23.4)$ & 18/158 (11.4) & 1.76 (1.01 to 3.08$)$ & $0.83(0)$ \\
\hline LC & 1 & 177 & 20/105 (19.0) & $9 / 72(12.5)$ & $1.52(0.74$ to 3.15$)$ & N/E \\
\hline LLETZ & 9 & 39249 & $877 / 10441(8.4)$ & $1511 / 28808(5.2)$ & $1.33(1.11$ to 1.6$)$ & $0.02(55)$ \\
\hline LA & 2 & 3326 & $115 / 1228(9.4)$ & $182 / 2098(8.7)$ & 1.05 (0.84 to 1.31$)$ & $0.45(0)$ \\
\hline RD & 1 & 2150 & $109 / 760(14.3)$ & $123 / 1390(8.8)$ & $1.62(1.27$ to 2.06$)$ & $\mathrm{N} / \mathrm{E}$ \\
\hline Excision NOS & 5 & 20321 & $756 / 7933(9.5)$ & $961 / 12388(7.8)$ & $1.23(1.07$ to 1.41$)$ & $0.2(33)$ \\
\hline Ablation NOS & 2 & 9470 & $131 / 2549(5.1)$ & $315 / 6921(4.6)$ & $1.00(0.74$ to 1.36$)$ & $0.18(45)$ \\
\hline \multicolumn{7}{|c|}{ All treatment types $v$ untreated HSIL } \\
\hline Overall & 3 & 3764 & $364 / 3022(12.0)$ & $58 / 742(7.8)$ & $1.37(0.85$ to 2.19$)$ & $0.05(53)$ \\
\hline CKC & 1 & 103 & $7 / 67(10.4)$ & $1 / 36(2.8)$ & $3.76(0.48$ to 29.39$)$ & $\mathrm{N} / \mathrm{E}$ \\
\hline NETZ & 1 & 109 & $17 / 71(23.9)$ & $2 / 38(5.3)$ & $4.55(1.11$ to 18.66$)$ & $\mathrm{N} / \mathrm{E}$ \\
\hline LLETZ & 1 & 881 & $55 / 572(9.6)$ & $12 / 309(3.9)$ & $2.48(1.35$ to 4.55$)$ & $\mathrm{N} / \mathrm{E}$ \\
\hline Excision NOS & 2 & 2275 & $247 / 1955(12.6)$ & $38 / 319(11.9)$ & $1.06(0.71$ to 1.59$)$ & $0.24(28)$ \\
\hline Ablation NOS & 2 & 397 & $38 / 357(10.6)$ & $5 / 40(12.5)$ & 0.68 (0.28 to 1.68$)$ & $0.87(0)$ \\
\hline \multicolumn{7}{|c|}{ Untreated women $v$ general population } \\
\hline Overall & 17 & 4359362 & $6261 / 105660(5.9)$ & $237203 / 4253702(5.6)$ & $1.24(1.14$ to 1.35$)$ & $<0.001(71)$ \\
\hline $\begin{array}{l}\text { Pregnancies before } \\
\text { treatment }\end{array}$ & 12 & 3134087 & $3893 / 60543(6.4)$ & $176453 / 3073544(5.7)$ & $1.26(1.08$ to 1.45$)$ & $0.03(49)$ \\
\hline $\begin{array}{l}\text { Untreated } \\
\text { colposcopy+/-biopsy }\end{array}$ & 4 & 1046823 & $2310 / 44375(5.2)$ & $49646 / 1002448(5.0)$ & $1.22(1.11$ to 1.34$)$ & $0.01(74)$ \\
\hline Untreated HSIL & 3 & 178452 & $58 / 742(7.8)$ & $11104 / 177710(6.2)$ & $1.40(0.94$ to 2.1$)$ & $0.08(59)$ \\
\hline
\end{tabular}

$\mathrm{CKC}=$ cold knife conisation; $\mathrm{CT}=$ cryotherapy; HSIL=high grade squamous intraepithelial lesion; $\mathrm{LA}=$ laser ablation; LC=laser conisation; LLETZ=large loop excision of transformation zone;

$\mathrm{N} / \mathrm{E}=$ not eligible; $\mathrm{NETZ}=$ needle excision of transformation zone; NOS=not otherwise specified; $\mathrm{RD}=$ radical diathermy.

should aim to correlate outcomes with precise prospective cone depth and cervical measurements.

Both the included and excluded studies showed a wide range of inclusion/exclusion criteria and outcome measures limiting statistical pooling of all the primary studies. There should be agreement among colposcopists and obstetricians on core research clinical outcome measures in line with the CROWN initiative of the premier reproductive health journals. ${ }^{134}$ This would improve the applicability of findings of primary and secondary research internationally.

\section{Interpretation in light of other evidence}

With an increasing evidence base suggesting that this risk is higher for more radical techniques, there has been a tendency to use less aggressive treatments. ${ }^{5}$ Although it was previously thought that the various techniques had comparable efficacy, ${ }^{135}$ evidence from a population 
based study raised concerns that less radical treatment could increase the risk of invasion after treatment. ${ }^{136137}$ Although the decreased number of hysterectomies could explain this increase, the move to less radical local conservative treatments is another plausible explanation. Additionally, since the first documentation of the reproductive risk associated with treatment almost a decade ago, ${ }^{1}$ subsequent observational studies and even meta-analyses reached contradictory conclusions ${ }^{2-416-19}$ and initiated debates within the scientific community. With some authors raising concerns that the progressive reduction in the radicality of treatment has led to increased risk of future of invasion, ${ }^{136137}$ and others advocating the move to less radical techniques like laser ablation for the prevention of future perinatal morbidity and mortality associated with treatment, ${ }^{138}$ high quality synthesis of the evidence had become an urgent unmet need. Some of the previous small meta-analyses had methodological flaws and attempted analysis of individual treatment techniques or subgroups, thereby minimising the validity of their findings in context with the rest of the literature. ${ }^{16-18}$ All the published meta-analyses failed to analyse the data according to major confounders and stratifiers of risk, the comparison group, and the depth of the excision. Although Bruinsma and Quinn first approached the comparison group as a possible confounder, data on the depth and dimensions of the treatment were not available. ${ }^{4}$

Preterm birth is a major cause of neonatal death and disability and represents an enormous cost to health services and society. While pregnant, these women with a history of cervical treatment make up a large proportion of referrals to specialist preterm labour prevention clinics. These referrals have increased from almost none in 1999, to more than 40\% in 2012. ${ }^{139}$ Ultrasound directed surveillance is labour intensive, costly, and can be associated with maternal anxiety, more so because $85 \%$ of women after excision are effectively low risk and will deliver at term. ${ }^{14}$

With rapidly accumulating evidence correlating cervical treatment to adverse reproductive morbidity, quantification of the comparative obstetric morbidity for different treatment techniques and cone depths is required to assist clinicians' decision making and counselling. The results of our meta-analysis will allow clinicians, patients, and policy makers to balance the absolute increase in reproductive morbidity with increasing treatment radicality. Patients should be informed that treatment increases the risk of preterm birth compared with having CIN only, but the absolute increase in risk in small type 1 excisions is likely to be low, if any.

Furthermore, the quantified individual risk stratified by treatment and cone depth could allow obstetricians to select women considered to be at high risk of preterm birth who would benefit from intensive surveillance antenatally and minimise the unnecessary interventions for those at low risk. The antenatal management of women after treatment has been inconsistent and largely unit or clinician dependent. ${ }^{30}$ The risks and benefits associated with various interventions in pregnant women with a history of cervical treatment have not been fully assessed in properly designed studies. ${ }^{140}$ Future research should assess their value in this distinct clinical group and devise a logical prevention strategy.

\section{Conclusion}

Women with CIN have a higher baseline risk of preterm birth than women from the general population. Local cervical treatment for preinvasive or early invasive disease further increases the risk, more so for excisional but also for ablative techniques. The risk of preterm birth increases with increasing cone depth (and volume) and techniques that remove or destroy larger parts of the cervix. The increase in risk for small excisions compared with having CIN is likely to be small, if any; more data are required.

In the decision to treat women of reproductive age, every effort should be made to perform a local treatment that will optimise the chances of a healthy pregnancy without compromising the completeness of the local treatment. Quality assurance in treatment of disease should include audit of dimensions of excisional specimens and persistent disease rates to ensure that treatment depth is kept to acceptable parameters (that is, at least $8 \mathrm{~mm}$ to include the crypts) and that oncological outcomes are not compromised.

Future research should investigate whether women who have preinvasive cervical disease are susceptible to both the disease and preterm birth, or whether HPV induced disease alone is the principal factor in increasing premature delivery. It is likely that a combination of immunological and other factors play a role. The uptake of prophylactic vaccination has been mixed in the developed world and minimal in low income countries. The impact of cervical treatment will continue to be relevant for many decades, and therefore robust clinical research in this field should remain a priority.

Contributors: The study was conceived and designed by MK, MA, PB, and EP. MK, AA, and MP acquired the data, which were collated and analysed by MK, AA, IK, and MA. All authors drafted and critically revised the manuscript for important intellectual content. MA, PB, and EP are joint senior authors. All authors gave final approval of the version to be published and have contributed to the manuscript. MK is guarantor.

Funding: This work was supported by the British Society of Colposcopy Cervical Pathology Jordan/Singer Award (P47773) (MK); the Imperial College Healthcare Charity (P47907) (AM and MK); Genesis Research Trust (P55549) (MK); Sigrid Jusélius Fellowship (P52483 to IK and MK), and the Imperial Healthcare NHS Trust NIHR Biomedical Research Centre (P45272) (MK, PRB). MA received support from the COHEAHR Network (grant No 603019), funded by Seventh Framework Programme of DG Research of the European Commission (Brussels); Institut National du Cancer (Paris) through the COSPCC study (Conséquences obstétricales du (sur)traitement des précurseurs du cancer du col); the European Federation of Colposcopy (Birmingham); and the Joint Action CANCON. None of the funders has any influence on the study design; in the collection, analysis, and interpretation of data; in the writing of the report; and in the decision to submit the article for publication.

Competing interests: All authors have completed the ICMJE uniform disclosure form at www.icmje.org/coi_disclosure.pdf and declare: no support from any organisation for the submitted work; no financial relationships with any organisations that might have an interest in the submitted work in the previous three years; no other relationships or activities that could appear to have influenced the submitted work.

Ethical approval: Not required.

Data sharing: No additional data available.

Transparency: The lead author affirms that the manuscript is an honest, accurate, and transparent account of the study being reported; that no important aspects of the study have been omitted; and that any discrepancies from the study as planned have been explained. 
This is an Open Access article distributed in accordance with the terms of the Creative Commons Attribution (CC BY 3.0) license, which permits others to distribute, remix, adapt and build upon this work, for commercial use, provided the original work is properly cited. See: http://creativecommons.org/licenses/by/3.0/.

1 Kyrgiou M, Koliopoulos G, Martin-Hirsch P, Arbyn M, Prendiville W, Paraskevaidis E. Obstetric outcomes after conservative treatment for intraepithelial or early invasive cervical lesions: systematic review and meta-analysis. Lancet 2006;367:489-98. doi:10.1016/ S0140-6736(06)68181-6.

2 Arbyn M, Kyrgiou M, Simoens C, et al. Perinatal mortality and other severe adverse pregnancy outcomes associated with treatment of cervical intraepithelial neoplasia: meta-analysis. BM 2008;337:a1284. doi:10.1136/bmj.a1284.

3 Kyrgiou M, Mitra A, Arbyn M, et al. Fertility and early pregnancy outcomes after treatment for cervical intraepithelial neoplasia: systematic review and meta-analysis. BMJ 2014;349:g6192. doi:10.1136/bmj.g6192.

4 Bruinsma FJ, Quinn MA. The risk of preterm birth following treatment for precancerous changes in the cervix: a systematic review and metaanalysis. BJOG 2011;118:1031-41. doi:10.1111/j.1471-0528.2011.02944.x.

5 Albrechtsen S, Rasmussen S, Thoresen S, Irgens LM, Iversen OE. Pregnancy outcome in women before and after cervical conisation: population based cohort study. BMJ 2008;337:a1343. doi:10.1136/ bmj.a1343.

6 Noehr B, Jensen A, Frederiksen K, Tabor A, Kjaer SK. Loop electrosurgical excision of the cervix and subsequent risk for spontaneous preterm delivery: a population-based study of singleton deliveries during a 9-year period. Am J Obstet Gynecol 2009;201:33. e1-6. doi:10.1016/j.ajog.2009.02.004

7 Kyrgiou M, Arbyn M, Martin-Hirsch P, Paraskevaidis E. Increased risk of preterm birth after treatment for CIN. BMJ 2012;345:e5847. doi:10.1136/bmj.e5847.

8 Phadnis SV, Atilade A, Bowring J, et al. Regeneration of cervix after excisional treatment for cervical intraepithelial neoplasia: a study of collagen distribution. Regeneration of cervix after excisional treatment for cervical intraepithelial neoplasia: a study of collagen distribution. BJOG 2011;118:1585-91. doi:10.1111/j.1471-0528.2011.03085.x.

9 Cervical Cancer Screening. Cervical Cancer Screening 2015 http:// www.cancerscreening.nhs.uk/cervical/.

10 Henk HJ, Insinga RP, Singhal PK, Darkow T. Incidence and costs of cervical intraepithelial neoplasia in a US commercially insured population. J Low Genit TractDis 2010;14:29-36. doi:10.1097/LGT.0b013e3181ac05e9.

11 Petry KU, Breugelmans JG, Bénard S, Lamure E, Littlewood KJ, Hillemanns P. Cost of screening and treatment of cervical dyskaryosis in Germany. Eur J Gynaecol Oncol 2008;29:345-9.

12 Jakobsson M, Gissler M, Sainio S, Paavonen J, Tapper AM. Preterm delivery after surgical treatment for cervical intraepithelial neoplasia. Obstet Gynecol 2007;109:309-13. doi:10.1097/01 AOG.0000253239.87040.23.

13 Ortoft G, Henriksen T, Hansen E, Petersen L. After conisation of the cervix, the perinatal mortality as a result of preterm delivery increases in subsequent pregnancy. BJOG 2010;117:258-67. doi:10.1111/j.1471-0528.2009.02438.x.

14 Reilly R, Paranjothy S, Beer H, Brooks CJ, Fielder HM, Lyons RA. Birth outcomes following treatment for precancerous changes to the cervix: a population-based record linkage study. BJOG 2012;119:236-44. doi:10.1111/j.1471-0528.2011.03052.x.

15 Castanon A, Brocklehurst P, Evans H, et al. PaCT Study Group. Risk of preterm birth after treatment for cervical intraepithelial neoplasia among women attending colposcopy in England: retrospectiveprospective cohort study. BMJ 2012;345:e5174. doi:10.1136/bmj.e5174.

16 Conner SN, Frey HA, Cahill AG, Macones GA, Colditz GA, Tuuli MG. Loop electrosurgical excision procedure and risk of preterm birth: a systematic review and meta-analysis. Obstet Gynecol 2014;123:75261. doi:10.1097/AOG.0000000000000174

17 Jin G, LanLan Z, Li C, Dan Z. Pregnancy outcome following loop electrosurgical excision procedure (LEEP) a systematic review and meta-analysis. Arch Gynecol Obstet 2014;289:85-99. doi:10.1007/ s00404-013-2955-0

18 Danhof NA, Kamphuis El, Limpens J, van Lonkhuijzen LR, Pajkrt E, Mol BW. The risk of preterm birth of treated versus untreated cervical intraepithelial neoplasia (CIN): a systematic review and meta-analysis. Eur J Obstet Gynecol Reprod Biol 2015;188:24-33. doi:10.1016/j. ejogrb.2015.02.033.

19 Crane JM. Pregnancy outcome after loop electrosurgical excision procedure: a systematic review. Obstet Gynecol 2003;102:1058-62.

20 Founta C, Arbyn M, Valasoulis G, et al. Proportion of excision and cervical healing after large loop excision of the transformation zone for cervical intraepithelial neoplasia. BJOG 2010;117:1468-74. doi:10.1111/j.1471-0528.2010.02709.x.

21 Kyrgiou M, Valasoulis G, Stasinou SM, et al. Proportion of cervical excision for cervical intraepithelial neoplasia as a predictor of pregnancy outcomes. Int J Gynaecol Obstet 2015;128:141-7. doi:10.1016/j.ijgo.2014.07.038.
22 Wells GA, Shea B, O'Connell D, et al. The Newcastle-Ottawa Scale (NOS) for assessing the quality of nonrandomised studies in meta-analyses. http://www.ohri.ca/programs/clinical epidemiology/nos manual.pdf.

23 Stroup DF, Berlin JA, Morton SC, et al. Meta-analysis of observational studies in epidemiology: a proposal for reporting. Meta-analysis of Observational Studies in Epidemiology (MOOSE) group. JAMA 2000;283:2008-12. doi:10.1001/jama.283.15.2008.

24 DerSimonian R, Laird N. Meta-analysis in clinical trials. Control Clin Trials 1986;7:177-88. doi:10.1016/0197-2456(86)90046-2.

25 Cochran WG. The combination of estimates from different experiments. Biometrics 1954;10:101-29. doi:10.2307/3001666

26 Higgins JP, Thompson SG, Deeks JJ, Altman DG. Measuring inconsistency in meta-analyses. BM/ 2003;327:557-60. doi:10.1136 bmj.327.7414.557.

27 Deeks J, Altman D, Bradburn M. Statistical methods for examining heterogeneity and combining results from several studies in meta-analysis.BMJ Publication Group, 2001. doi:10.1002/9780470693926.ch15.

28 Jones JM, Sweetnam P, Hibbard BM. The outcome of pregnancy after cone biopsy of the cervix: a case-control study. Br J Obstet Gynaecol 1979;86:913-6. doi:10.1111/j.1471-0528.1979.tb11237.x.

29 Weber T, Obel EB. Pregnancy complications following conization of the uterine cervix (II). Acta Obstet Gynecol Scand 1979;58:347-51. doi:10.3109/00016347909154594.

30 Buller RE, Jones HW 3rd. Pregnancy following cervical conization. Am J Obstet Gynecol 1982;142:506-12. doi:10.1016/0002-9378(82)90752-9.

31 Hemmingsson E. Outcome of third trimester pregnancies after cryotherapy of the uterine cervix. Br J Obstet Gynaecol 1982;89:675-7. doi:10.1111/j.1471-0528.1982.tb04725.x.

32 Larsson G, Grundsell H, Gullberg B, Svennerud S. Outcome of pregnancy after conization. Acta Obstet Gynecol Scand 1982;61:461-6. doi:10.3109/00016348209156591.

33 Ludviksson K, Sandström B. Outcome of pregnancy after cone biopsy-a case-control study. Eur J Obstet Gynecol Reprod Biol 1982;14:135-42. doi:10.1016/0028-2243(82)90088-0.

34 Moinian M, Andersch B. Does cervix conization increase the risk of complications in subsequent pregnancies? Acta Obstet Gynecol Scand 1982:61:101-3. doi:10.3109/00016348209156537.

35 Anderson MC, Horwell DH, Broby Z. Outcome of pregnancy after laser vaporization conization. J Gynecol Surg 1984;1:35-9. doi:10.1089/ gyn.1984.1.35

36 Kristensen GB. The outcome of pregnancy and preterm delivery after conization of the cervix. Arch Gynecol 1985;236:127-30. doi:10.1007/ BF02133954.

37 Kuoppala T, Saarikoski S. Pregnancy and delivery after cone biopsy of the cervix. Arch Gynecol 1986;237:149-54. doi:10.1007/BF02133858.

38 Saunders N, Fenton DW, Soutter WP, Brown VA, Sharp F, Abernethy F. A case controlled study of the outcome of pregnancy following laser vapourization cone of the cervix. In: Sharp F, Jordan JA, eds. Gynaecological laser surgery: Proceedings of the Fifteenth Study Group of the Royal College of Obstetricians and Gynaecologists Reproductive and perinatal medicine (VI). Ithaca, New York: Perinatology Press; 1986:121-5.

39 Gunasekera PC, Lewis BV, Phipps JH. Obstetric outcome after cervical surgery for intra-epithelial neoplasia. J Obstet Gynaecol 1992;12:291-3. doi:10.3109/01443619209015508.

40 Blomfield PI, Buxton J, Dunn J, Luesley DM. Pregnancy outcome after large loop excision of the cervical transformation zone. Am / Obstet Gynecol 1993;169:620-5. doi:10.1016/0002-9378(93)90633-T.

41 Haffenden DK, Bigrigg A, Codling BW, Read MD. Pregnancy following large loop excision of the transformation zone. Br J Obstet Gynaecol 1993;100:1059-60. doi:10.1111/j.1471-0528.1993.tb15153.x.

42 Hagen B, Skjeldestad FE. The outcome of pregnancy after CO2 laser conisation of the cervix. Br J Obstet Gynaecol 1993;100:717-20. doi:10.1111/j.1471-0528.1993.tb14261.x

43 Kristensen J, Langhoff-Roos J, Kristensen FB. Increased risk of preterm birth in women with cervical conization. Obstet Gynecol 1993;81:1005-8

44 Braet PG, Peel JM, Fenton DW. A case controlled study of the outcome of pregnancy following loop diathermy excision of the transformation zone. J Obstet Gynaecol 1994;14:79-82. doi:10.3109/01443619409030016.

45 Cruickshank ME, Flannelly G, Campbell DM, Kitchener HC. Fertility and pregnancy outcome following large loop excision of the cervical transformation zone. BrJ Obstet Gynaecol 1995;102:467-70. doi:10.1111/j.1471-0528.1995.tb11319.x.

46 Sagot P, Caroit Y, Winer N, Lopes P, Boog G. Obstetrical prognosis for carbon dioxide laser conisation of the uterine cervix. Eur J Obstet Gynecol Reprod Biol 1995;58:53-8. doi:10.1016/0028-2243(94)01986-H.

47 Spitzer M, Herman J, Krumholz BA, Lesser M. The fertility of women after cervical laser surgery. Obstet Gynecol 1995;86:504-8. doi:10.1016/0029-7844(95)00237-L.

48 Békássy Z, losif CS. Laser ‘miniconisation’ and the outcome of subsequent pregnancy. Arch Gynecol Obstet 1996;258:75-9.

49 Forsmo S, Hansen MH, Jacobsen BK, Oian P. Pregnancy outcome after laser surgery for cervical intraepithelial neoplasia. Acta Obstet Gynecol Scand 1996;75:139-43. doi:10.3109/00016349609033306. 
50 Turlington WT, Wright BD, Powell JL. Impact of the loop electrosurgical excision procedure on future fertility. J Reprod Med 1996;41:815-8.

51 Raio L, Ghezzi F, Di Naro E, Gomez R, Lüscher KP. Duration of pregnancy after carbon dioxide laser conization of the cervix: influence of cone height. Obstet Gynecol 1997;90:978-82. doi:10.1016/S0029-7844(97)00489-4

52 Andersen ES, Pedersen B, Boris J. Pregnancy outcome after combination laser conization: a case-control study. J Gynecol Surg 1999;15:7-12. doi:10.1089/gyn.1999.15.7

53 El-Bastawissi AY, Becker TM, Daling JR. Effect of cervical carcinoma in situ and its management on pregnancy outcome. Obstet Gynecol 1999;93:207-12

54 van Rooijen M, Persson E. Pregnancy outcome after laser vaporization of the cervix. Acta Obstet Gynecol Scand 1999;78:346-8. doi:10.1034/j.1600-0412.1999.780414.X

55 Paraskevaidis E, Koliopoulos G, Lolis E, Papanikou E, Malamou-Mitsi V, Agnantis NJ. Delivery outcomes following loop electrosurgical excision procedure for microinvasive (FIGO stage IA1) cervical cancer. Gynecol Oncol 2002;86:10-3. doi:10.1006/gyno.2002.6650.

56 Sadler L, Saftlas A, Wang W, Exeter M, Whittaker J, McCowan L. Treatment for cervical intraepithelial neoplasia and risk of preterm delivery. JAMA 2004;291:2100-6. doi:10.1001/jama.291.17.2100.

57 Tan L, Pepra E, Haloob RK. The outcome of pregnancy after large loop excision of the transformation zone of the cervix. J Obstet Gynaecol 2004;24:25-7. doi:10.1080/01443610310001620242

58 Acharya G, Kjeldberg I, Hansen SM, Sørheim N, Jacobsen BK, Maltau JM. Pregnancy outcome after loop electrosurgical excision procedure for the management of cervical intraepithelial neoplasia. Arch Gynecol Obstet 2005;272:109-12. doi:10.1007/ s00404-005-0727-1.

59 Samson SL, Bentley JR, Fahey TJ, McKay DJ, Gill GH. The effect of loop electrosurgical excision procedure on future pregnancy outcome. Obstet Gynecol 2005;105:325-32. doi:10.1097/01. AOG.0000151991.09124.bb.

60 Crane JM, Delaney T, Hutchens D. Transvaginal ultrasonography in the prediction of preterm birth after treatment for cervical intraepithelial neoplasia. Obstet Gynecol 2006;107:37-44. doi:10.1097/01. AOG.0000192169.44775.76.

61 Klaritsch P, Reich O, Giuliani A, Tamussino K, Haas J, Winter R. Delivery outcome after cold-knife conization of the uterine cervix. Gynecol Oncol 2006;103:604-7. doi:10.1016/j.ygyno.2006.04.003.

62 Bruinsma F, Lumley J, Tan J, Quinn M. Precancerous changes in the cervix and risk of subsequent preterm birth. BJOG 2007;114:70-80. doi:10.1111/j.1471-0528.2006.01107x

63 Himes KP, Simhan HN. Time from cervical conization to pregnancy and preterm birth. Obstet Gynecol 2007;109:314-9. doi:10.1097/01. AOG.0000251497.55065.74.

64 Sjøborg KD, Vistad I, Myhr SS, et al. Pregnancy outcome after cervical cone excision: a case-control study. Acta Obstet Gynecol Scand 2007;86:423-8. doi:10.1080/11038120701208158.

65 Parikh R, Horne H, Feinstein SI, Anasti JN. Cervical length screening in patients who have undergone loop electrosurgical excision procedure. J Reprod Med 2008;53:909-13.

66 Jakobsson M, Gissler M, Paavonen J, Tapper AM. Loop electrosurgical excision procedure and the risk for preterm birth. Obstet Gynecol 2009;114:504-10. doi:10.1097/ AOG.0b013e3181b052de.

67 Noehr B, Jensen A, Frederiksen K, Tabor A, Kjaer SK. Loop electrosurgical excision of the cervix and subsequent risk for spontaneous preterm delivery: a population-based study of singleton deliveries during a 9-year period. Am J Obstet Gynecol 2009;201:33. e1-6. doi:10.1016/j.ajog.2009.02.004

68 Noehr B, Jensen A, Frederiksen K, Tabor A, Kjaer SK. Depth of cervical cone removed by loop electrosurgical excision procedure and subsequent risk of spontaneous preterm delivery. Obstet Gynecol 2009;114:1232-8. doi:10.1097/AOG.0b013e3181bf1ef2.

69 Noehr B, Jensen A, Frederiksen K, Tabor A, Kjaer SK. Loop electrosurgical excision of the cervix and risk for spontaneous preterm delivery in twin pregnancies. Obstet Gynecol 2009;114:511-5. doi:10.1097/AOG.0b013e3181b1377b.

70 Shanbhag S, Clark H, Timmaraju V, Bhattacharya S, Cruickshank M. Pregnancy outcome after treatment for cervical intraepithelial neoplasia. Obstet Gynecol 2009;114:727-35. doi:10.1097/ AOG.0b013e3181b5cba3.

71 Fischer RL, Sveinbjornsson G, Hansen C. Cervical sonography in pregnant women with a prior cone biopsy or loop electrosurgical excision procedure. Ultrasound Obstet Gynecol 2010;36:613-7. doi:10.1002/uog.7682

72 van de Vijver A, Poppe W, Verguts J, Arbyn M. Pregnancy outcome after cervical conisation: a retrospective cohort study in the Leuven University Hospital. BJOG 2010;117:268-73. doi:10.1111/j.1471-0528.2009.02437.x

73 Werner CL, Lo JY, Heffernan T, Griffith WF, McIntire DD, Leveno KJ. Loop electrosurgical excision procedure and risk of preterm birth. Obstet Gynecol 2010;115:605-8. doi:10.1097/

AOG.0b013e3181d068a3.
74 Andía D, Mozo de Rosales F, Villasante A, Rivero B, Díez J, Pérez C. Pregnancy outcome in patients treated with cervical conization for cervical intraepithelial neoplasia. Int / Gynaecol Obstet 2011;112:2258. doi:10.1016/j.ijgo.2010.10.015

75 Armarnik S, Sheiner E, Piura B, Meirovitz M, Zlotnik A, Levy A. Obstetric outcome following cervical conization. Arch Gynecol Obstet 2011:283:765-9 doi:10.1007/s00404-011-1848-3.

76 Lima AF, Francisco C, Júlio C, Paula T, Vitorino A, Borrego J. Obstetric outcomes after treatment for cervical intraepithelial neoplasia: six years of experience. / Low Genit Tract Dis 2011;15:276-9. doi:10.1097/ LGT.0b013e31821a6823.

77 Poon LC, Savvas M, Zamblera D, Skyfta E, Nicolaides KH. Large loop excision of transformation zone and cervical length in the prediction of spontaneous preterm delivery. BJOG 2012;119:692-8. doi:10.1111/j.1471-0528.2011.03203.x

78 Simoens C, Goffin F, Simon P, et al. Adverse obstetrical outcomes after treatment of precancerous cervical lesions: a Belgian multicentre study. BJOG 2012;119:1247-55 doi:10.1111/j.1471-0528.2012.03429.x

79 Van Hentenryck M, Noel JC, Simon P. Obstetric and neonatal outcome after surgical treatment of cervical dysplasia. Eur J Obstet Gynecol Reprod Biol 2012;162:16-20. doi:10.1016/j. ejogrb.2012.01.019.

80 Frega A, Sesti F, De Sanctis L, et al. Pregnancy outcome after loop electrosurgical excision procedure for cervical intraepithelial neoplasia. Int J Gynaecol Obstet 2013;122:145-9. doi:10.1016/j. ijgo.2013.03.013.

81 Frey HA, Stout MJ, Odibo AO, et al. Risk of cesarean delivery after loop electrosurgical excision procedure. Obstet Gynecol 2013;121:39-45. doi:10.1097/AOG.0b013e318278f904.

82 Guo HJ, Guo RX, Liu YL. Effects of loop electrosurgical excision procedure or cold knife conization on pregnancy outcomes. Eur) Gynaecol Oncol 2013;34:79-82.

83 Heinonen A, Gissler M, Riska A, Paavonen J, Tapper AM, Jakobsson M. Loop electrosurgical excision procedure and the risk for preterm delivery. Obstet Gynecol 2013;121:1063-8. doi:10.1097/ AOG.0b013e31828caa31.

84 Wuntakal R, Castanon A, Sasieni PD, Hollingworth A. Pregnancy outcomes after treatment for cervical intraepithelial neoplasia in a single NHS hospital. Int J Gynecol Cancer 2013;23:710-5. doi:10.1097/ IGC.0b013e3182885496.

85 Castanon A, Landy R, Brocklehurst P, et al. PaCT Study Group. Risk of preterm delivery with increasing depth of excision for cervical intraepithelial neoplasia in England: nested case-control study. BMJ 2014;349:g6223. doi:10.1136/bmj.g6223.

86 Ciavattini A, Stortoni P, Mancioli F, Puglia D, Tranquilli AL, Liverani CA. The impact of loop electrosurgical excision procedure (LEEP) for CIN 2,3 on spontaneous preterm delivery in twin pregnancies by assisted reproductive technique: preliminary data. J Matern Fetal Neonatal Med 2014;27:1169-71 doi:10.3109/14767058.2013.850483.

87 Ehsanipoor RM, Jolley JA, Goldshore MA, et al. The relationship between previous treatment for cervical dysplasia and preterm delivery in twin gestations. I Matern Fetal Neonatal Med 2014;27:8214. doi:10.3109/14767058.2013.836178.

88 Kitson SJ, Greig E, Michael E, Smith M. Predictive value of volume of cervical tissue removed during LLETZ on subsequent preterm delivery: a cohort study. Eur J Obstet Gynecol Reprod Biol 2014;180:51-5. doi:10.1016/j.ejogrb.2014.06.011.

89 Sozen H, Namazov A, Cakir S, Akdemir Y, Vatansever D, Karateke A. Pregnancy outcomes after cold knife conization related to excised cone dimensions. A retrospective cohort study. J Reprod Med 2014;59:81-6.

90 Martyn FM, McAuliffe FM, Beggan C, Downey P, Flannelly G, Wingfield MB. Excisional treatments of the cervix and effect on subsequent fertility: a retrospective cohort study. Eur J Obstet Gynecol Reprod Biol 2015;185:114-20. doi:10.1016/j. ejogrb.2014.12.004.

91 Stout MJ, Frey HA, Tuuli MG, et al. Loop electrosurgical excision procedure and risk of vaginal infections during pregnancy: an observational study. BJOG 2015;122:545-51. doi:10.1111/1471-0528.13252.

92 Kirn V, Geiger P, Riedel C, et al. Cervical conisation and the risk of preterm delivery: a retrospective matched pair analysis of a German cohort. Arch Gynecol Obstet 2015;291:599-603. doi:10.1007/ s00404-014-3463-6.

93 Miller ES, Sakowicz A, Grobman WA. The association between cervical dysplasia, a short cervix, and preterm birth. Am J Obstet Gynecol 2015;213:543.e1-4. doi:10.1016/j.ajog.2015.06.036.

94 Macvicar J, Willocks J. The effect of diathermy conization of the cervix on subsequent fertility, pregnancy and delivery. J Obstet Gynaecol Br Commonw 1968;75:355-6. doi:10.1111/j.1471-0528.1968. tb02090.x.

95 Kullander S, Sjöberg NO. Treatment of carcinoma in situ of the cervix uteri by conization. A five-year follow-up. Acta Obstet Gynecol Scand 1971:50:153-7. doi:10.3109/00016347109157302. 
96 Grönroos M, Liukko P, Kilkku P, Punnonen R. Pregnancy and delivery after conization of the cervix. Acta Obstet Gynecol Scand 1979;58:47780. doi:10.3109/00016347909154071.

97 Leiman G, Harrison NA, Rubin A. Pregnancy following conization of the cervix: complications related to cone size. Am J Obstet Gynecol 1980;136:14-8. doi:10.1016/0002-9378(80)90556-6.

98 Monaghan JM, Kirkup W, Davis JA, Edington PT. Treatment of cervical intraepithelial neoplasia by colposcopically directed cryosurgery and subsequent pregnancy experience. Br J Obstet Gynaecol 1982;89:38792. doi:10.1111/j.1471-0528.1982.tb05082.x

99 Wakita K, Izumi T, Kuramoto H, Sasaki N, Shimada N. Pregnancy after laser therapy for the treatment of uterine cervical neoplasia. J Clin Laser Med Surg 1990;8:71-6.

100 Novikova EG, Antoshechkina MA. [Reproductive function after the organ-preserving treatment of early cancerous pathology of the cervix uteri]. Akush Ginekol (Mosk) 1994;2:44-7.

101 Mitsuhashi A, Sekiya S. Loop electrosurgical excision procedure (LEEP) during first trimester of pregnancy. Int J Gynaecol Obstet 2000;71:237-9. doi:10.1016/S0020-7292(99)00173-3.

102 Althuisius SM, Schornagel IJ, Dekker GA, van Geijn HP, Hummel P. Loop electrosurgical excision procedure of the cervix and time of delivery in subsequent pregnancy. Int J Gynaecol Obstet 2001;72:31-4. doi:10.1016/S0020-7292(00)00326-X

103 Berghella V, Pereira L, Gariepy A, Simonazzi G. Prior cone biopsy: prediction of preterm birth by cervical ultrasound. Am J Obstet Gynecol 2004;191:1393-7. doi:10.1016/j.ajog.2004.06.087.

104 Masamoto H, Nagai Y, Inamine M, et al. Outcome of pregnancy after laser conization: implications for infection as a causal link with preterm birth. J Obstet Gynaecol Res 2008;34:838-42. doi:10.1111/j.1447-0756.2008.00852.x.

105 Patrelli TS, Anfuso S, Vandi F, et al. Preterm delivery and premature rupture of membranes after conization in 80 women. Preliminary data. Minerva Ginecol 2008;60:295-8

106 Michelin MA, Merino LM, Franco CA, Murta EF. Pregnancy outcome after treatment of cervical intraepithelial neoplasia by the loop electrosurgical excision procedure and cold knife conization. Clin Exp Obstet Gynecol 2009;36:17-9.

107 Nam KH, Kwon JY, Kim YH, Park YW. Pregnancy outcome after cervical conization: risk factors for preterm delivery and the efficacy of prophylactic cerclage. J Gynecol Oncol 2010;21:225-9. doi:10.3802/ igo.2010.21.4.225

108 Radha Bai Prabhu T. Pregnancy outcome following large loop excision of the transformation zone (LLETZ). J Obstet Gynaecol India 2010;60:149-51. doi:10.1007/s13224-010-0022-3.

109 Seki N, Kodama J, Kusumoto T, Nakamura K, Hongo A, Hiramatsu Y. Complications and obstetric outcomes after laser conization during pregnancy. Eur J Gynaecol Oncol 2010;31:399-401.

110 Shin MY, Seo ES, Choi SJ, et al. The role of prophylactic cerclage in preventing preterm delivery after electrosurgical conization. J Gynecol Oncol 2010;21:230-6. doi:10.3802/jgo.2010.21.4.230.

111 Khalid S, Dimitriou E, Conroy R, et al. The thickness and volume of LLETZ specimens can predict the relative risk of pregnancy-related morbidity. BJOG 2012;119:685-91. doi:10.1111/j.1471-0528.2011.03252.x.

112 Berretta R, Gizzo S, Dall'Asta A, et al. Risk of preterm delivery associated with prior treatment of cervical precancerous lesion according to the depth of the cone. Dis Markers 2013;35:721-6. doi:10.1155/2013/686027.

113 Conner SN, Cahill AG, Tuuli MG, et al. Interval from loop electrosurgical excision procedure to pregnancy and pregnancy outcomes. Obstet Gynecol 2013;122:1154-9. doi:10.1097/01 AOG.0000435454.31850.79.

114 Liu Y, Qiu HF, Tang Y, Chen J, Lv J. Pregnancy outcome after the treatment of loop electrosurgical excision procedure or cold-knife conization for cervical intraepithelial neoplasia. Gynecol Obstet Invest 2014:77:240-4. doi:10.1159/000360538

115 Rafaeli-Yehudai T, Kessous R, Aricha-Tamir B, et al. The effect of cervical cerclage on pregnancy outcomes in women following conization. J Matern Fetal Neonatal Med 2014;27:1594-7. doi:10.3109/14767058.2013.871254.

116 Sangkarat S, Ruengkhachorn I, Benjapibal M, Laiwejpithaya S, Wongthiraporn W, Rattanachaiyanont M. Long-term outcomes of a loop electrosurgical excision procedure for cervical intraepithelial neoplasia in a high incidence country. Asian Pac J Cancer Prev 2014;15:1035-9. doi:10.7314/APJCP.2014.15.2.1035.

117 Wongtiraporn W, Laiwejpithaya S, Sangkarat S, et al. Long term outcomes of laser conization for high grade cervical intraepithelial neoplasia in Thai women. Asian Pac J Cancer Prev 2014;15:7757-61. doi:10.7314/APJCP.2014.15.18.7757.

118 Kim M, Ishioka S, Endo T, Baba T, Saito T. Obstetrical prognosis of patients with cervical intraepithelial neoplasia (CIN) after "coinshaped” conization. Arch Gynecol Obstet 2016;293:651-7. doi:10.1007/s00404-015-3860-5.
119 Anwar A, Igbenehi C, Lindow SW, Noor N, Musa S, Saha A. Pregnancy outcome after electrosurgical cervical cone biopsy using Fischer cone biopsy excisor. J Matern Fetal Neonatal Med 2016;29:477-81. doi:10.3109/14767058.2015.1006619.

120 Rosen A, Klein M, Vavra N, et al. [PAP IV in pregnancy--a retrospective multicenter study]. Geburtshilfe Frauenheilkd 1991;51:208-10. doi:10.1055/s-2007-1023705.

121 Sljivancanin D, Kesić V, Tulić L, Dotlić ]. [Assessment of the natural course and treatment of premalignant uterine cervical lesions in pregnancy]. Srp Arh Celok Lek 2013:141:192-7. doi:10.2298/SARH1304192S.

122 Ricciotti HA, Burke L, Kobelin M, Slomovic B, Ludmir J. Ultrasound evaluation of cervical shortening after loop excision of the transformation zone (LETZ). Int J Gynaecol Obstet 1995;50:175-8. doi:10.1016/0020-7292(95)02432-C.

123 Gentry DJ, Baggish MS, Brady K, Walsh PM, Hungler MS. The effects of loop excision of the transformation zone on cervical length: implications for pregnancy. Am J Obstet Gynecol 2000;182:516-20 doi:10.1067/mob.2000.104209.

124 Kalliala I, Anttila A, Dyba T, Hakulinen T, Halttunen M, Nieminen P. Pregnancy incidence and outcome among patients with cervical intraepithelial neoplasia: a retrospective cohort study. BJOG 2012;119:227-35. doi:10.1111/j.1471-0528.2011.03042.x.

125 Spracklen CN, Harland KK, Stegmann BJ, Saftlas AF. Cervical surgery for cervical intraepithelial neoplasia and prolonged time to conception of a live birth: a case-control study. BJOG 2013;120:960-5 doi:10.1111/1471-0528.12209.

126 Ciavattini A, Clemente N, Delli Carpini G, et al. Loop electrosurgical excision procedure and risk of miscarriage. Fertil Steril 2015;103:1043-8. doi:10.1016/j.fertnstert.2014.12.112

127 Naleway AL, Weinmann S, Krishnarajah G, et al. Pregnancy after treatment for cervical cancer precursor lesions in a retrospective matched cohort. PLoS One 2015;10:e0117525. doi:10.1371/journal. pone. 0117525

128 Pils S, Eppel W, Seemann R, Natter C, Ott J. Sequential cervical length screening in pregnancies after loop excision of the transformation zone conisation: a retrospective analysis. BJOG 2014;121:457-62 doi:10.1111/1471-0528.12390.

129 Pinborg A, Ortoft G, Loft A, Rasmussen SC, Ingerslev HJ. Cervical conization doubles the risk of preterm and very preterm birth in assisted reproductive technology twin pregnancies. Hum Reprod 2015;30:197-204. doi:10.1093/humrep/deu260.

130 Smaldone GM, Krohn MA, McGee EA. Cervical cancer and risk for delivery of small-for-gestational age neonates. I Womens Health (Larchmt) 2010;19:969-74. doi:10.1089/jwh.2009.1574.

131 Zuo Z, Goel S, Carter JE. Association of cervical cytology and HPV DNA status during pregnancy with placental abnormalities and preterm birth. Am J Clin Pathol 2011;136:260-5. doi:10.1309/AJCP93JMIUEKRPIW.

$132 \mathrm{Al}$-Halal H, Kezouh A, Abenhaim HA. Incidence and obstetrical outcomes of cervical intraepithelial neoplasia and cervical cancer in pregnancy: a population-based study on 8.8 million births. Arch Gynecol Obstet 2013;287:245-50. doi:10.1007/s00404-012-2475-3.

133 Moher D, Liberati A, Tetzlaff J, Altman DG, Group P. PRISMA Group. Preferred reporting items for systematic reviews and meta-analyses: the PRISMA Statement. Open Med 2009;3:e123-30

134 http://www.crown-initiative.org/aims-and-scope/

135 Martin-Hirsch PP, Paraskevaidis E, Bryant A, Dickinson HO. Surgery for cervical intraepithelial neoplasia. Cochrane Database Syst Rev 2013;12:CD001318.

136 Strander B, Hällgren J, Sparén P. Effect of ageing on cervical or vaginal cancer in Swedish women previously treated for cervical intraepithelia neoplasia grade 3: population based cohort study of long term incidence and mortality. BMJ 2014;348:f7361. doi:10.1136/bmj.f7361.

137 Arbyn M, Kyrgiou M, Gondry J, Petry KU, Paraskevaidis E. Long term outcomes for women treated for cervical precancer. $B M$ J 2014:348:f7700, doi:10.1136/bmi.f7700.

138 Paraskevaidis E, Kyrgiou M, Martin-Hirsch P. Have we dismissed ablative treatment too soon in colposcopy practice? BJOG 2007:114:3-4. doi:10.1111/j.1471-0528.2006.01178.x.

139 Kindinger L, Teoh T. Preterm delivery - who is most at risk? An audit of a preterm surveillance clinic. BJOG 2013;120(Supplement 3):50.

140 Kindinger L, Kyrgiou M, MacIntyre D, et al. Pregnancy outcome after cervical treatment for $\mathrm{CIN}$ : management of the risk of preterm delivery by ultrasound measurement of cervical length and targeted cervical cerclage. PLoS One [forthcoming].

(c) BMJ Publishing Group Ltd 2016

Appendix 1: Search strategy

Appendix 2: Supplementary tables A-F

Appendix 3: Forest plot for all treatment techniques 